\title{
Metabolic View on Human Healthspan: A Lipidome-Wide Association Study
}

\author{
Justin Carrard ${ }^{1,+} \mathbb{D}$, Hector Gallart-Ayala ${ }^{2,+}$, Denis Infanger ${ }^{1}$, Tony Teav ${ }^{2}$, Jonathan Wagner ${ }^{1}$, Raphael Knaier ${ }^{1}$, \\ Flora Colledge ${ }^{3}$, Lukas Streese ${ }^{1}$, Karsten Königstein ${ }^{1}$, Timo Hinrichs ${ }^{1}$, Henner Hanssen ${ }^{1}$, \\ Julijana Ivanisevic $2, *, \ddagger \subset$ and Arno Schmidt-Trucksäss ${ }^{1, *, \ddagger}$
}

1 Division of Sports and Exercise Medicine, Department of Sport, Exercise and Health, University of Basel, Birsstrasse 320B, CH-4052 Basel, Switzerland; justin.carrard@unibas.ch (J.C.); denis.infanger@unibas.ch (D.I.); jonathan.wagner@unibas.ch (J.W.); raphael.knaier@unibas.ch (R.K.); lukas.streese@unibas.ch (L.S.); k.koenigstein@unibas.ch (K.K.); timo.hinrichs@unibas.ch (T.H.); henner.hanssen@unibas.ch (H.H.)

2 Metabolomics Platform, Faculty of Biology and Medicine, University of Lausanne, Quartier UNIL-CHUV, Rue du Bugnon 19, CH-1005 Lausanne, Switzerland; hector.gallartayala@unil.ch (H.G.-A.); tony.teav@unil.ch (T.T.)

3 Division of Sports Science, Department of Sport, Exercise and Health, University of Basel, Birsstrasse 320B, CH-4052 Basel, Switzerland; flora.colledge@unibas.ch

* Correspondence: julijana.ivanisevic@unil.ch (J.I.); arno.schmidt-trucksaess@unibas.ch (A.S.-T.)

+ First authors, equally contributed.

$\ddagger$ Last authors, equally contributed.

check for updates

Citation: Carrard, J.; Gallart-Ayala, H.; Infanger, D.; Teav, T.; Wagner, J.; Knaier, R.; Colledge, F.; Streese, L.; Königstein, K.; Hinrichs, T.; et al. Metabolic View on Human Healthspan: A Lipidome-Wide Association Study. Metabolites 2021, 11, 287. https://doi.org/10.3390/ metabo11050287

Academic Editor: Amedeo Lonardo

Received: 3 April 2021

Accepted: 28 April 2021

Published: 30 April 2021

Publisher's Note: MDPI stays neutral with regard to jurisdictional claims in published maps and institutional affiliations.

Copyright: (c) 2021 by the authors. Licensee MDPI, Basel, Switzerland. This article is an open access article distributed under the terms and conditions of the Creative Commons Attribution (CC BY) license (https:/ / creativecommons.org/licenses/by/ $4.0 /)$.

\begin{abstract}
As ageing is a major risk factor for the development of non-communicable diseases, extending healthspan has become a medical and societal necessity. Precise lipid phenotyping that captures metabolic individuality could support healthspan extension strategies. This study applied 'omic-scale lipid profiling to characterise sex-specific age-related differences in the serum lipidome composition of healthy humans. A subset of the COmPLETE-Health study, composed of 73 young (25.2 \pm 2.6 years, $43 \%$ female) and 77 aged (73.5 \pm 2.3 years, $48 \%$ female) clinically healthy individuals, was investigated, using an untargeted liquid chromatography high-resolution mass spectrometry approach. Compared to their younger counterparts, aged females and males exhibited significant higher levels in 138 and 107 lipid species representing 15 and 13 distinct subclasses, respectively. Percentage of difference ranged from $5.8 \%$ to $61.7 \%$ (females) and from $5.3 \%$ to $46.0 \%$ (males), with sphingolipid and glycerophophospholipid species displaying the greatest amplitudes. Remarkably, specific sphingolipid and glycerophospholipid species, previously described as cardiometabolically favourable, were found elevated in aged individuals. Furthermore, specific ether-glycerophospholipid and lyso-glycerophosphocholine species displayed higher levels in aged females only, revealing a more favourable lipidome evolution in females. Altogether, age determined the circulating lipidome composition, while lipid species analysis revealed additional findings that were not observed at the subclass level.
\end{abstract}

Keywords: healthspan; healthy population study; metabolic phenotyping; lipidomics; serum lipid signature

\section{Introduction}

The ageing of the world's population contributes largely to the growing prevalence of non-communicable diseases [1]. Simultaneously, disease-specific healthcare approaches tend to foster survival with chronic diseases and disabilities rather than contributing to a longer healthy life, referred to as healthspan [1-6]. As a result, ageing and related morbidities impose an increasing socio-economic burden on nations [7]. Thus, the World Health Organization (WHO) launched the concept of healthy ageing, which focuses on the preservation of physiological functions across the course of life to increase healthspan [1,2]. To implement this concept into clinical practice, new phenotyping tools that could capture 
metabolic individuality and stratify patients with respect to potential health decline and disease onset, are needed $[8,9]$.

Total cholesterol, low-density lipoprotein cholesterol (LDL-C), high-density lipoprotein cholesterol (HDL-C) and triglycerides are still the main lipid markers used to assess cardiometabolic risk in clinical medicine $[10,11]$. However, the human plasma lipidome is estimated to consist of hundreds of thousands of lipid species, which are extremely diverse in both chemical structures and biological functions [12]. Following the technological advances in mass spectrometry and bioinformatics, lipidomics has evolved into a high-throughput approach to allow for an in-depth investigation of lipid metabolism-at the species level [13,14]. In light of their involvement in numerous biological processes, lipids are believed to act as key modulators of health, ageing and pathogenesis of cardiometabolic diseases $[12,15,16]$. Indeed, lipids are essential to energy storage, cell structure and molecular signalling [12,17]. They are the main constituents of plasma membranes, where they modulate receptor activity and vesicular trafficking $[18,19]$. The term bioactive lipid is used to designate lipid species in which a change in abundance leads to functional repercussions [20]. Sphingolipids in general, and ceramides in particular, form an important category of bioactive lipids, as they modulate numerous critical biological processes and have been implicated in many cardiometabolic, oncological and neurodegenerative disorders [20-22]. For instance, ceramides located at the surface of low-density lipoproteins (LDL) drive their aggregation and transcytosis through the endothelium as well as uptake into macrophages, which leads to foam cell formation and vascular inflammation [23-25]. Remarkably, plasma ceramides are strong predictors of cardiovascular death in patients with and without coronary artery disease [26-29]. Therefore, ceramides could become the "new cholesterol" in daily clinical practice [30].

In view of these findings, 'omic-scale lipid analysis shows potential for improving clinical patients' stratification $[13,14,31]$. However, prior to profiling patients, clinical studies investigating healthy populations are necessary to decipher the relations between circulatory lipid species and key biological determinants, such as age and sex. This is essential to further elucidate the role of the many lipid species in health maintenance. Investigating healthy aged individuals enables the disentanglement of age- from disease-related metabolic changes, which is rarely done as most human ageing studies enrolled patients already suffering from chronic diseases or centenarians of unspecified or poorly characterised health status [32-46]. Moreover, the few studies which claimed to have examined the metabolic profile of healthy individuals did not report on or adjust for physical activity levels [47-50]. Considering that physical inactivity has been recognised as the fourth leading cause of death worldwide, it is coherent to consider physical activity as a key determinant of human health [51,52].

This cross-sectional population-based study had two aims. Firstly, to acquire the serum lipid profile of clinically healthy humans in their twenties and seventies using an untargeted liquid chromatography high-resolution mass spectrometry approach. Secondly, to identify lipid species associated with age and sex [53]. To this end, sera of a subset of the COmPLETE-Health study, composed of young (20-29 years) and aged (70-79 years) well characterised, clinically healthy females and males, were investigated [54].

\section{Results}

\subsection{Characteristics of the Clinically Healthy Participants}

The examined subset consisted of 73 young ( $25.2 \pm 2.6$ years, $44 \%$ female) and 77 aged (73.5 \pm 2.3 years, $48 \%$ female) participants of the COmPLETE-Health study. Participants underwent objective physical activity tracking, blood sampling and lipid phenotyping (Figure 1A). Categorised by age and sex, each group displayed, on average, normal to high-normal blood pressure, and normal body mass index, triglycerides and glycated haemoglobin (HbA1c) levels (Table 1) $[10,55,56]$. The aged participants exhibited slightly elevated mean LDL-C levels compared to the maximal recommended value of $3 \mathrm{mmol} / \mathrm{L}$ for low-risk patients [10]. In each group, the mean fasting time prior to blood sampling was 
$5.6 \mathrm{~h}$ at least. All participants fulfilled the WHO recommendations in terms of daily physical activity time (moderate-to-vigorous physical activity ranging from 39.1 to $321.4 \mathrm{~min} /$ day, with a mean of $158.9 \pm 57.1 \mathrm{~min} /$ day) [52]. Clinical data distribution is presented in Figure S1.

A

Subset of the COmPLETE

\section{Clinical phenotyping}

Study design Health study

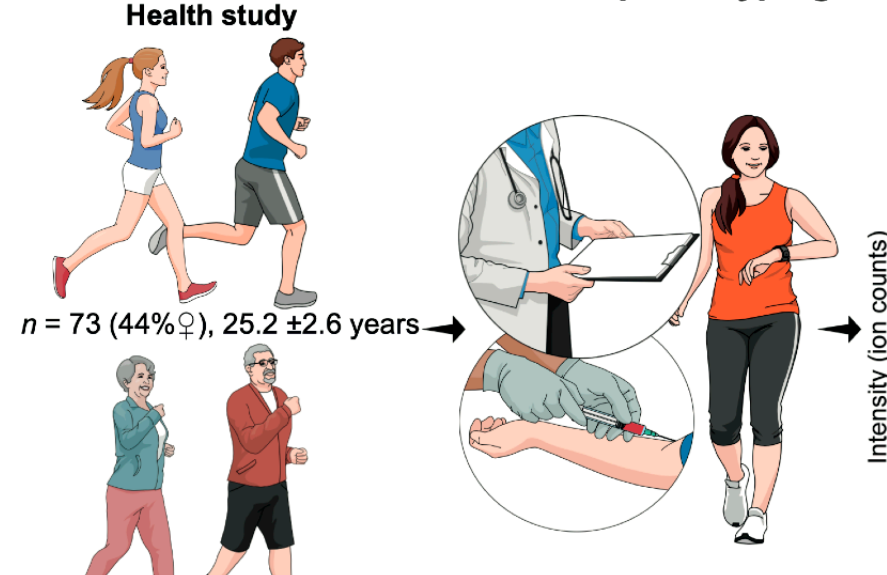

e.g. physical activity tracking and blood sampling

$n=77(48 \%$ \&), $73.5 \pm 2.3$ years

\section{B}

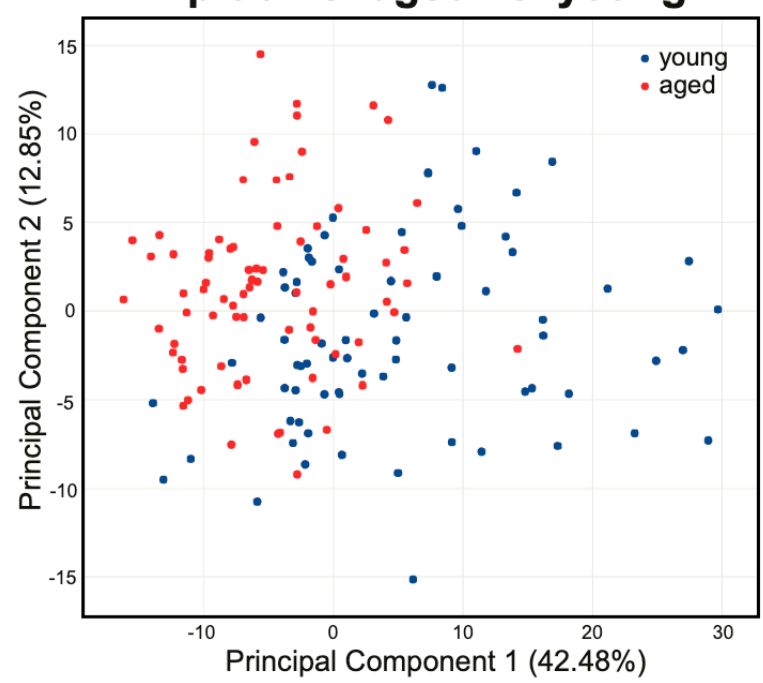

\section{Lipid phenotyping}

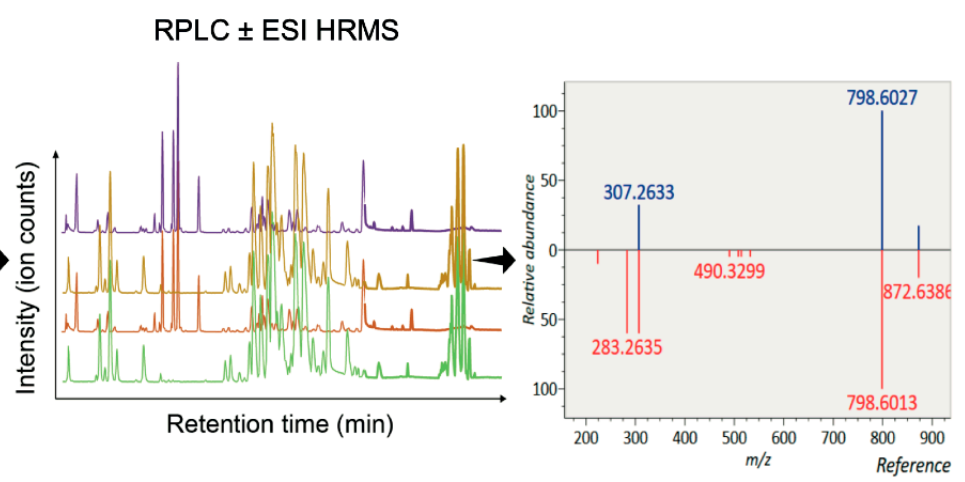

Serum lipidomic signature

Lipid annotation

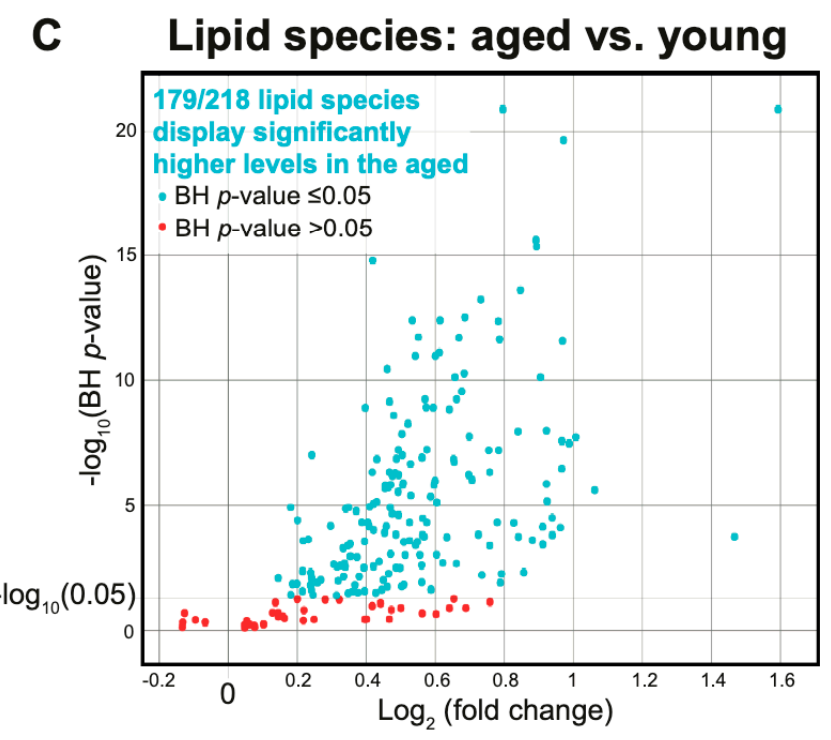

Figure 1. Study design, principal component analysis and differential analysis. (A) Overview of the study design including physical activity tracking and lipid phenotyping. (B) Principal component analysis highlighting the difference in lipid profile between young and aged participants. (C) Differential analysis highlighting lipid species displaying significantly higher levels (adjusted $p$-value $\leq 0.05$ ) in the aged compared to the young participants after correction for blood sampling time. Abbreviations: RPLC \pm ESI HRMS = Reversed-Phase Liquid Chromatography Electrospray Ionisation High-Resolution Mass Spectrometry; $m / z=$ mass to charge ratio; $\mathrm{BH}=$ Benjamini-Hochberg. Panel A was created in the Mind the Graph platform (www.mindthegraph.com (accessed on 15 July 2020)). 
Table 1. Participants' characteristics.

\begin{tabular}{|c|c|c|c|c|}
\hline & \multicolumn{2}{|c|}{ Young } & \multicolumn{2}{|c|}{ Aged } \\
\hline & Female & Male & Female & Male \\
\hline Participants, $n$ (\%) & $32(21.3)$ & $41(27.3)$ & $37(24.7)$ & $40(26.7)$ \\
\hline \multicolumn{5}{|l|}{ Anthropometry, mean \pm SD } \\
\hline Age (years) & $25.1 \pm 2.3$ & $25.1 \pm 2.8$ & $74.0 \pm 2.4$ & $73.9 \pm 2.5$ \\
\hline Body mass (kg) & $60.5 \pm 9.0$ & $76.7 \pm 9.5$ & $61.8 \pm 7.5$ & $74.9 \pm 8.3$ \\
\hline Body fat mass $(\%)$ & $23.1 \pm 6.9$ & $14.7 \pm 5.3$ & $30.4 \pm 7.5$ & $24.3 \pm 6.1$ \\
\hline Body mass index $\left(\mathrm{kg} / \mathrm{m}^{2}\right)$ & $21.5 \pm 2.9$ & $23.7 \pm 2.3$ & $23.5 \pm 3.0$ & $24.9 \pm 2.6$ \\
\hline Systolic blood pressure (mmHg) & $111 \pm 8$ & $126 \pm 10$ & $137 \pm 12$ & $133 \pm 13$ \\
\hline Diastolic blood pressure (mmHg) & $71 \pm 8$ & $71 \pm 7$ & $80 \pm 8$ & $82 \pm 8$ \\
\hline \multicolumn{5}{|l|}{ Smoking status, $n$ (\%) } \\
\hline Never smoked & $31(97)$ & $40(98)$ & $26(70)$ & $21(52)$ \\
\hline Ex-smokers (quit > 10 years ago) & $1(3)$ & $1(2)$ & $11(30)$ & $19(48)$ \\
\hline \multicolumn{5}{|l|}{ Physical activity (PA) levels, mean \pm SD } \\
\hline Daily total PA (min) & $282.3 \pm 56.1$ & $274.7 \pm 69.3$ & $257.2 \pm 87.3$ & $237.7 \pm 75.2$ \\
\hline Daily moderate-to-vigorous PA (min) & $190.7 \pm 45.1$ & $186.7 \pm 53.1$ & $142.4 \pm 63.0$ & $140.8 \pm 55.3$ \\
\hline \multicolumn{5}{|l|}{ Biochemical parameters, mean \pm SD } \\
\hline Fasting time prior to blood sampling (h) & $6.0 \pm 1.6$ & $5.6 \pm 2.0$ & $6.6 \pm 3.7$ & $7.4 \pm 4.5$ \\
\hline Total cholesterol $(\mathrm{mmol} / \mathrm{L})$ & $4.96 \pm 0.78$ & $4.68 \pm 0.95$ & $6.49 \pm 0.80$ & $5.96 \pm 1.11$ \\
\hline LDL-C $(\mathrm{mmol} / \mathrm{L})$ & $2.62 \pm 0.48$ & $2.52 \pm 0.56$ & $3.56 \pm 0.59$ & $3.40 \pm 0.73$ \\
\hline HDL-C (mmol/L) & $1.81 \pm 0.42$ & $1.43 \pm 0.24$ & $1.91 \pm 0.35$ & $1.58 \pm 0.33$ \\
\hline Triglycerides (mmol/L) & $1.08 \pm 0.53$ & $1.33 \pm 0.80$ & $1.41 \pm 1.06$ & $1.35 \pm 0.45$ \\
\hline $\mathrm{HbA} 1 \mathrm{c}(\%)$ & $5.0 \pm 0.2$ & $5.0 \pm 0.2$ & $5.4 \pm 0.3$ & $5.3 \pm 0.3$ \\
\hline \multicolumn{5}{|l|}{ Cardiovascular medications, $n(\%)$} \\
\hline Antihypertensives & $0(0)$ & $0(0)$ & $9(16)$ & $19(35)$ \\
\hline Low-dose aspirin & $0(0)$ & $0(0)$ & $2(5)$ & $4(10)$ \\
\hline Statins & $0(0)$ & $0(0)$ & $3(8)$ & $6(15)$ \\
\hline \multicolumn{5}{|l|}{ Hormonal medications, $n(\%)$} \\
\hline Oestrogen/HRT & $4(13)$ & $0(0)$ & $5(14)$ & $0(0)$ \\
\hline $5 \alpha$-reductase inhibitors & $0(0)$ & $0(0)$ & $0(0)$ & $4(10)$ \\
\hline Thyroid hormones & $0(0)$ & $0(0)$ & $3(8)$ & $3(8)$ \\
\hline \multicolumn{5}{|l|}{ Psychiatric medications, $n$ (\%) } \\
\hline Antidepressants & $1(3)$ & $1(2)$ & $1(3)$ & $0(0)$ \\
\hline Z-drugs & $0(0)$ & $0(0)$ & $3(8)$ & $0(0)$ \\
\hline Other medications, $n$ (\%) & $3(9)$ & $6(12)$ & $31(49)$ & $24(42)$ \\
\hline
\end{tabular}

Abbreviations: LDL-C = low-density lipoprotein cholesterol, HDL-C = low-density lipoprotein cholesterol, HbA1c = glycated hemoglobin, HRT = hormone replacement therapy, Z-drugs = nonbenzodiazepine benzodiazepine receptor agonists. Other drugs include: vitamins (19), nonsteroidal anti-inflammatory drugs (8), proton-pump inhibitors (7), topical ophthalmic drugs (7), antihistamines (4), tamsulosin (3), melatonin (2), anthocyanosides of vaccinium myrtillus (1), clindamycin (1), fluticasone/salmeterol (1), fluticasone/vilanterol (1), ibandronate (1), mesalazine (1), mometasone (1), paracetamol (1), prednisolone (1), pregabalin (1), tiotropium (1), zoledronate (1).

\subsection{Lipid Signature of Clinically Healthy Young and Aged Phenotypes}

As shown in Table 2, 218 lipid species belonging to 16 distinct lipid subclasses were identified with a high level of confidence (using accurate $m / z$ ratio and MS/MS fragmentation pattern). Principal Component Analysis (PCA) revealed that young and aged participants displayed two distinct serum lipid signatures (PC1 42.48\%, PC2 12.85\%, Figure 1B and Table S1), while differential analysis showed that 179 lipid species exhibited higher levels in aged compared to young participants (Figure 1C and Table S2). After adjustment for body fat (\%), statins intake, HbA1c (\%), daily total physical activity (min), blood sampling time and fasting time prior to blood sampling, 12 of 16 lipid subclasses were significantly and positively associated with age (Figure 2 and Table S3). The strongest associations were observed for lyso-alkyl-glycerophosphoethanolamines (LPE-O, $\beta$ coefficient $=1.49$, Benjamini-Hochberg $(\mathrm{BH}) p$-value $\leq 0.0001$ ), glycerophosphoinositols (PI, $\beta$ coefficient $=1.43, \mathrm{BH} p$-value $\leq 0.0001)$, ceramides $(\mathrm{Cer}, \beta$ coefficient $=1.41$, 
BH $p$-value $\leq 0.0001)$ and sphingomyelins (SM, $\beta$ coefficient $=1.40$, BH $p$-value $\leq 0.0001)$. On the molecular level, 121 species (including 28 glycerophosphocholines, PC, and $23 \mathrm{SMs}$ ) were significantly and positively associated with age (Table S4). The strongest associations were observed for PC(16:0_18:0) ( $\beta$ coefficient $=1.67$, BH $p$-value $\leq 0.0001)$ and $\operatorname{SM}(37: 2 ; 3)$ ( $\beta$ coefficient $=1.67, \mathrm{BH} p$-value $\leq 0.0001)$. Strikingly, no lipid subclass or species was significantly and negatively associated with age. Daily total physical activity did not display any significant association with any lipid species or subclass (Tables S3 and S4).

Table 2. Identified lipid species and their respective lipid subclass.

\begin{tabular}{ccc}
\hline $\begin{array}{c}\text { Lipid Subclass, } \\
\text { Full Name }\end{array}$ & $\begin{array}{c}\text { Lipid Subclass, } \\
\text { Abbreviation }\end{array}$ & Identified Lipid Species, $\boldsymbol{n}$ \\
\hline Diglycerides & DG & 2 \\
Triglycerides & TG & 58 \\
Cholesterol esters & CE & 5 \\
Glycerophosphocholines & PC & 42 \\
Alkyl-glycerophosphocholines & PC-O & 16 \\
Lyso-glycerophosphocholines & LPC & 15 \\
Glycerophosphoinositols & PI & 7 \\
Lyso-glycerophosphoinositols & LPI & 2 \\
Glycerophospoethanolamines & PE & 11 \\
Alkyl-glycerophosphoethanolamines & PE-O & 15 \\
Alkenyl-glycerophosphoethanolamines & PE-P & 1 \\
Lyso-glycerophosphoethanolamines & LPE & 7 \\
Lyso-alkyl-glycerophosphoethanolamines & LPE-O & 2 \\
Ceramides & Cer & 6 \\
Sphingomyelins & SM & 24 \\
Glycosphingolipids & GSL & 5 \\
\hline
\end{tabular}

Post-hoc tests were calculated to determine and compare the estimated marginal means of each lipid in aged and young participants within both sexes, using the emmeans R-package (version 1.4.8) [57]. They revealed that the subclasses SM, Cer, PI, glycosphingolipids (GSL), PC and lyso-glycerophosphoinositols (LPI) displayed, in both sexes, significantly higher levels in aged compared to young participants (Figures S2 and S3, Table S5). In females, 138 lipid species (including 32 PCs and $23 \mathrm{SMs}$ ) showed significantly higher levels in aged compared to young participants, with the percentage of difference ranging from $5.8 \%$ to $61.7 \%$ (Figure $3 \mathrm{~A}$ and Table S6). In males, 107 lipid species (including 28 PCs and $23 \mathrm{SMs}$ ) exhibited significantly higher levels in aged compared to young subjects, with the percentage of difference ranging from 5.3\% to $46.0 \%$ (Figure 3B and Table S6). In both females and males, $\mathrm{SM}(37: 2 ; 3)$ displayed the greatest percentage of difference (females: $61.7 \%$, BH $p$-value $\leq 0.0001$; males: $46.0 \%$, BH $p$-value $\leq 0.0001$ ). No lipid subclass or species was significantly decreased with age in both females and males. 


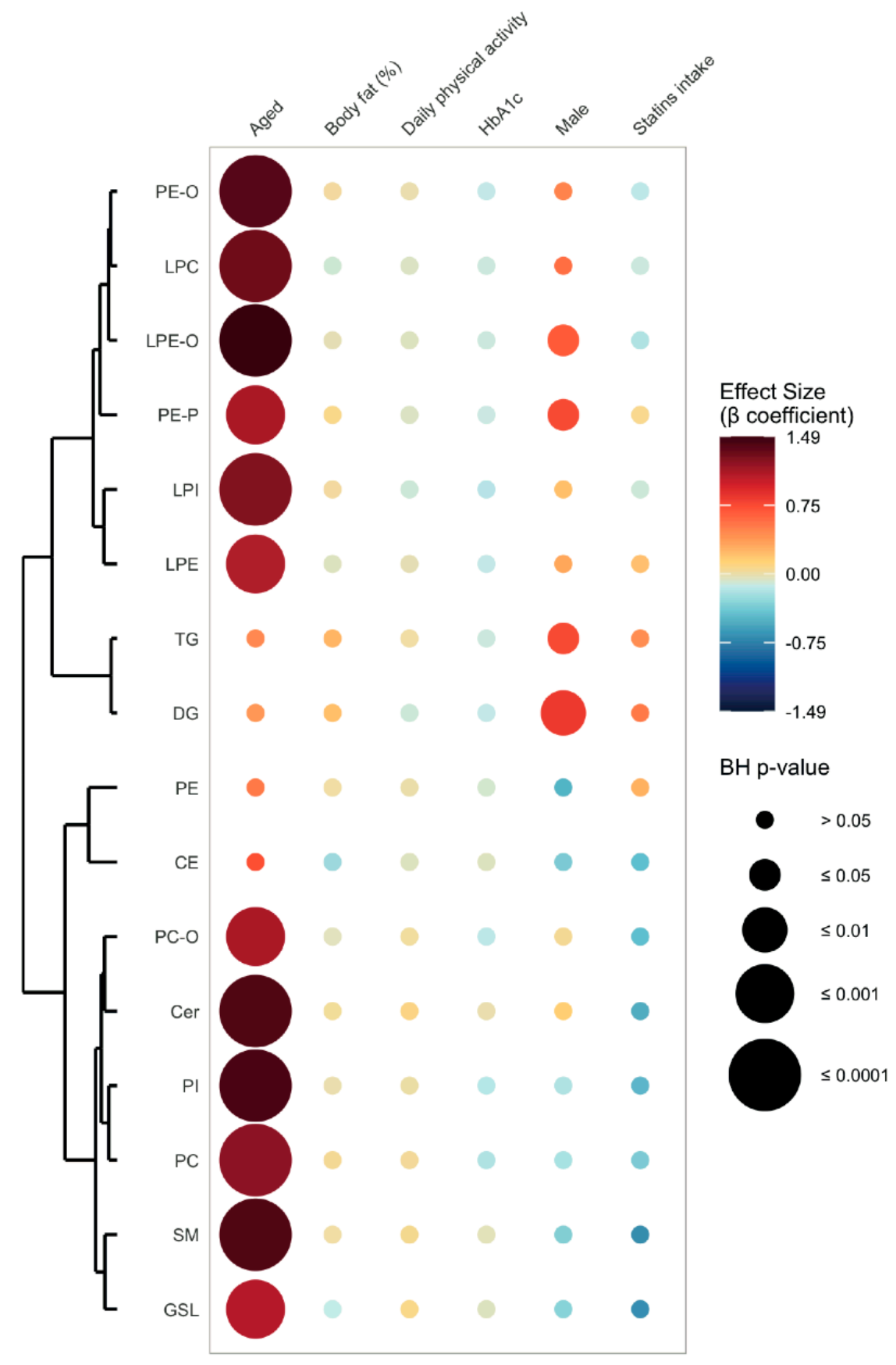

Figure 2. Associations between lipid subclasses, age, sex and clinical variables. Abbreviations: $\mathrm{BH}$ = Benjamini-Hochberg, DG = diglycerides, TG = triglycerides, CE = cholesterol esters, LPC = lysoglycerophosphocholines, $\mathrm{PC}=$ glycerophosphocholines, $\mathrm{PC}-\mathrm{O}=$ alkyl-glycerophosphocholines, LPE = lyso-glycerophosphoethanolamines, LPE-O = lyso-alkyl-glycerophosphoethanolamines, $\mathrm{PE}=$ glycerophospoethanolamines, $\mathrm{PE}-\mathrm{O}=$ alkyl-glycerophosphoethanolamines, $\mathrm{PE}-\mathrm{P}=$ alkenylglycerophosphoethanolamines, LPI = lyso-glycerophosphoinositols, PI = glycerophosphoinositols, Cer = ceramides, GSL = glycosphingolipids, $\mathrm{SM}=$ sphingomyelins, MUFA = monounsaturated fatty acid, PUFA = polyunsaturated fatty acids, $\mathrm{HbA1c}=$ glycated haemoglobin. 
A Females

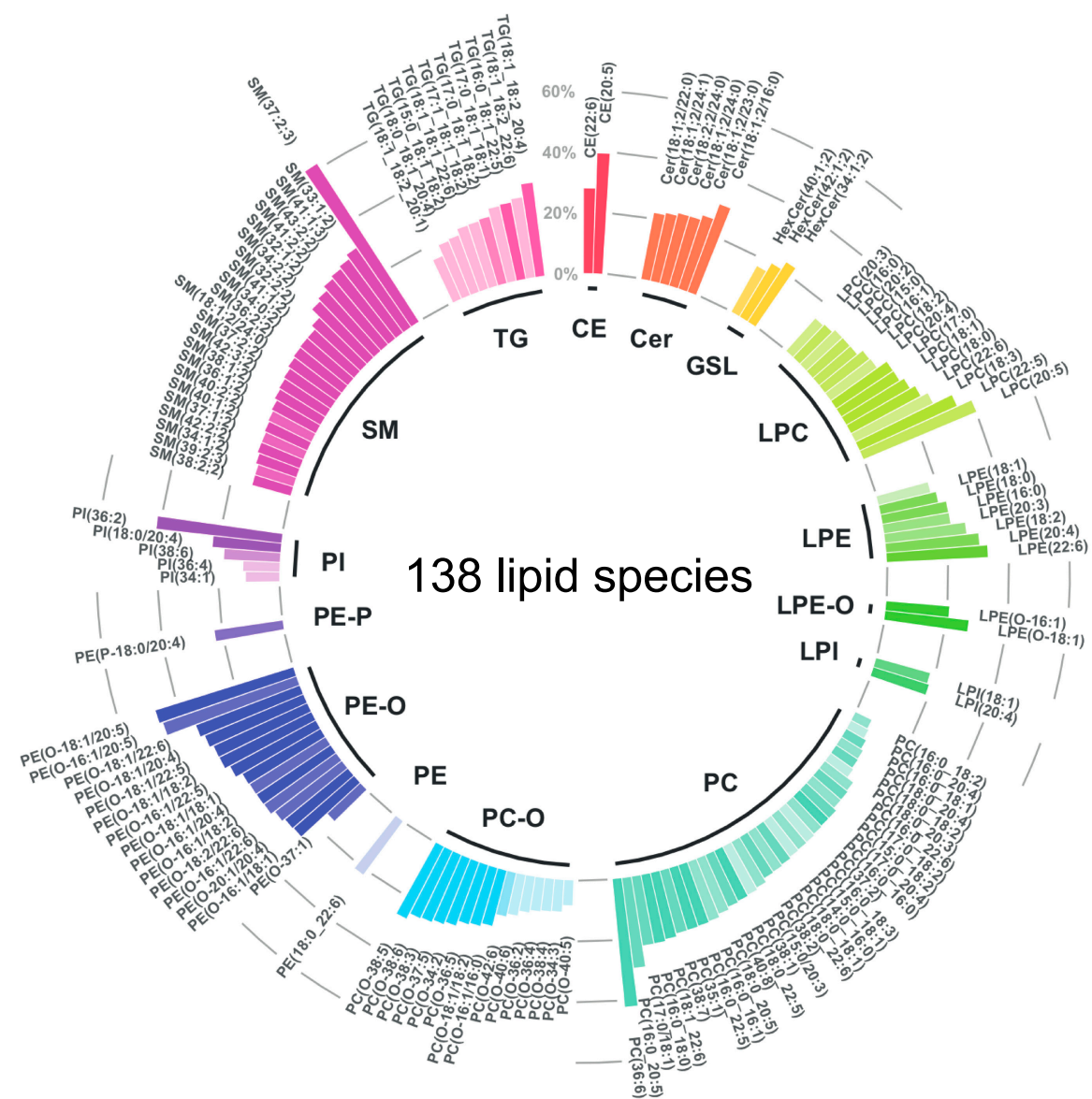

B

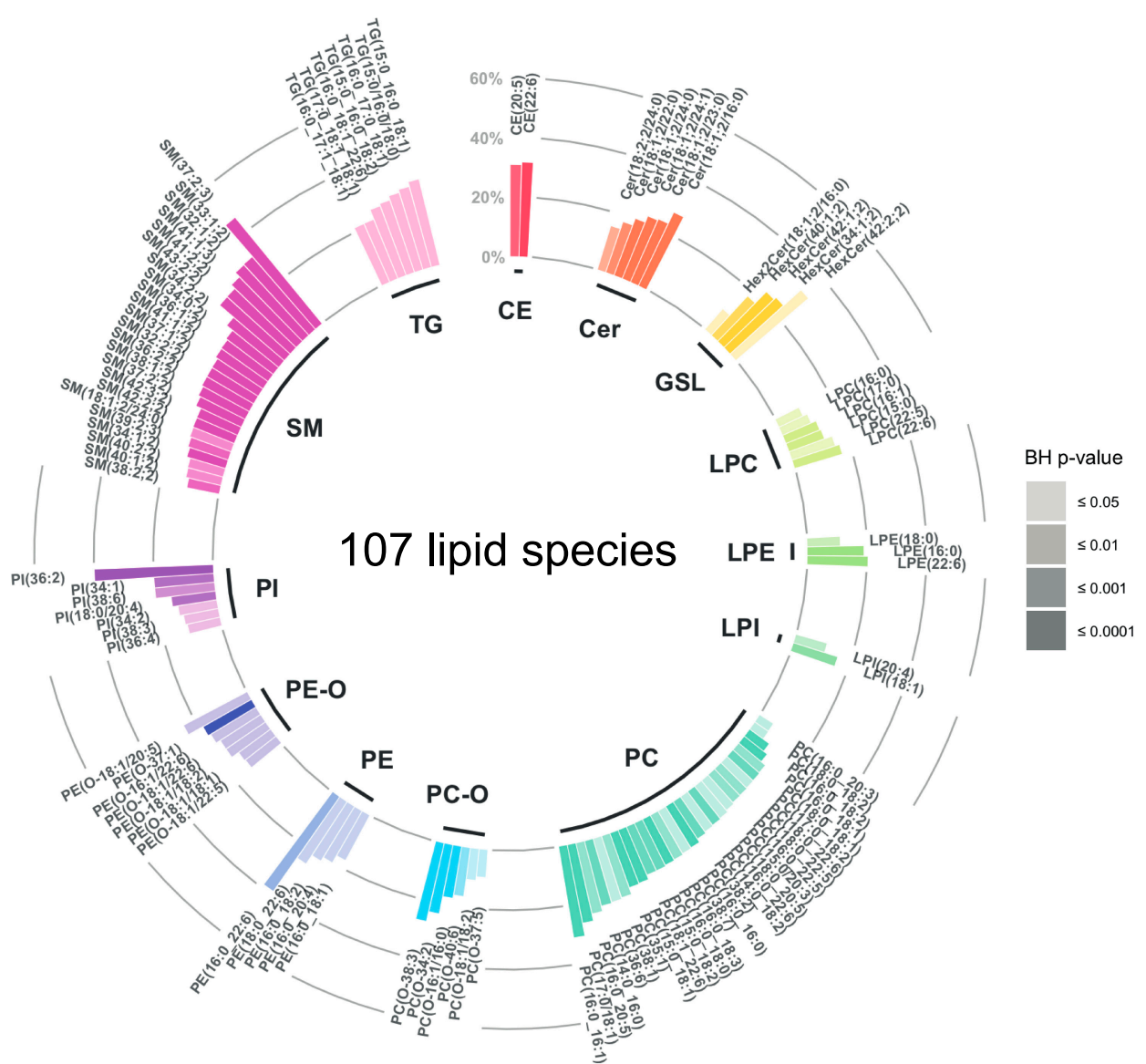

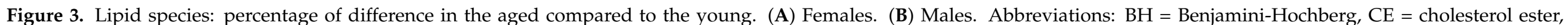

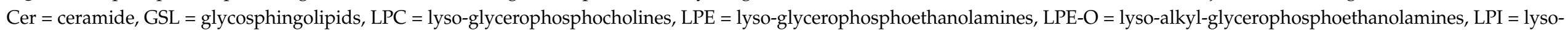

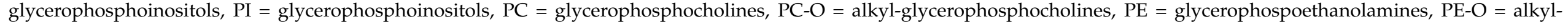
glycerophosphoethanolamines, $\mathrm{PI}=$ glycerophosphoinositols, $\mathrm{SM}=$ sphingomyelins and TG = triglycerides. 
Regarding the saturation level, age was negatively associated with the monounsaturated fatty acid (MUFA) to polyunsaturated fatty acids (PUFA) ratio for PI (Figure S4 and Table S7). Post-hoc tests revealed that the MUFA/PUFA ratios for PI and lysoglycerophosphoethanolamines (LPE) were significantly lower in aged compared to young females, while the MUFA/PUFA ratio for Cer was significantly higher in aged compared to young males (Figure S5 and Table S8). Concerning glycerophosphocholines (PC) to glycerophosphoethanolamines (PE) ratios, age was negatively associated with the ratio alkyl-glycerophosphocholines (PC-O) to alkyl-glycerophosphoethanolamines (PE-O, Figure S6 and Table S9). Post-hoc tests revealed that the PC-O/PE-O ratio was significantly lower in aged compared to young females (Figure S7 and Table S10).

Lipid ontology (LION) enrichment analysis was conducted using LION/web (version 2020.07.14), which is an online tool performing network analysis within the lipidomic dataset [58]. Containing a library of $>50,000$ lipid species, LION/web goes beyond classical analysis solely based on lipid nomenclature by providing insights whether specific physicochemical properties, biological functions or cellular localisation are enriched in a given group or condition of interest. Thus, LION/web aims to facilitate the interpretation of complex lipidomic datasets within a biological context. All 218 lipid species could be matched with a LION ID within the LION library. Twenty-three LION terms were significantly enriched in aged compared to young females (Figure 4A and Table S11), with "1-alkyl,2-acylglycerophosphoethanolamines" (PE-O) being the most enriched LION term (15 matches, $q$-value $\leq 0.0001)$. In males, nine LION terms were significantly enriched in the aged compared to the young (Figure $4 \mathrm{~B}$ and Table S12), with "sphingolipids" being the most enriched LION term ( 35 matches, $q$-value $\leq 0.0001$ ).

A

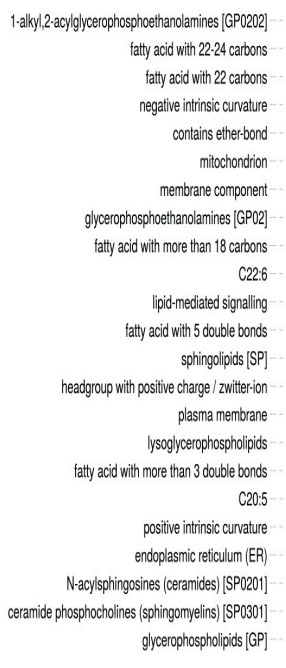

B

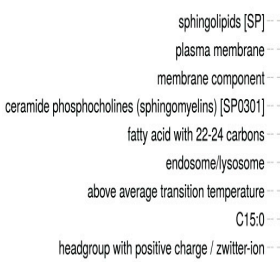

\section{Females}

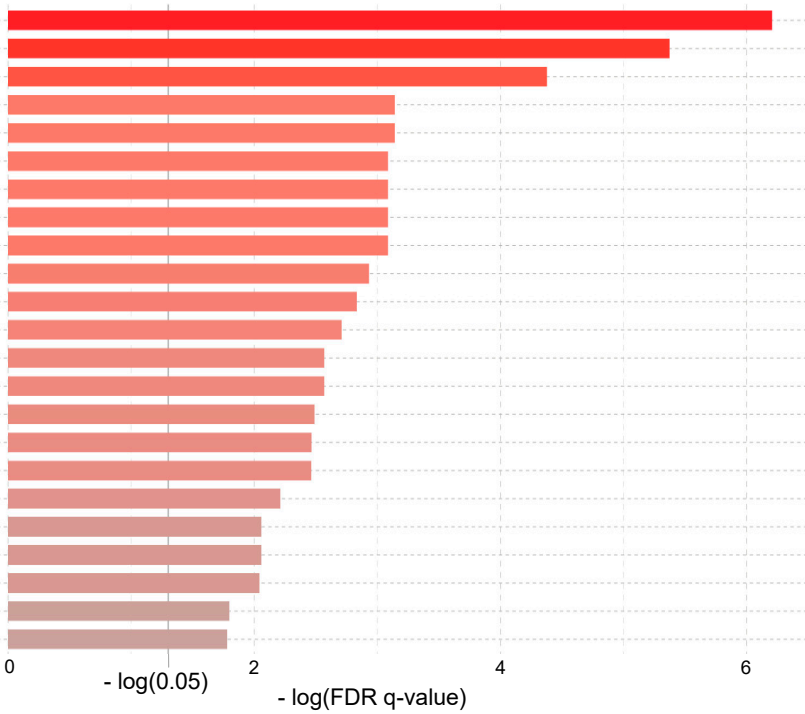

Males

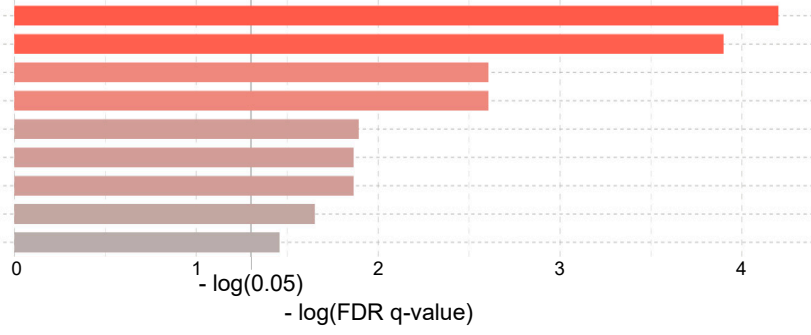

Figure 4. Lipid ontology enrichment analysis: aged compared to young. (A) Females. (B) Males. Abbreviations: $\mathrm{FDR}=$ false discovery rate. 


\subsection{Age-Related Sex Differences in the Circulatory Lipidome Composition}

The subclasses diglycerides (DG), TG, alkenyl-glycerophosphoethanolamines (PE$\mathrm{P})$ and LPE-O as well as 23 species (including 17 TGs) were significantly and positively associated with the male sex (Figure 2, Tables S3 and S4). Conversely, $\operatorname{SM}(32: 2 ; 2), \operatorname{SM}(38: 2 ; 2)$, PC(16:0_16:1), PE(16:0_22:6), PI(34:1) and PC(O-34:2) were significantly and negatively associated with the male sex (Table S4).

Within the young participants, 15 lipid species (including six SMs and three PCs) exhibited higher levels in females compared to males (Figure S8 and Table S6). Conversely, the subclasses DG, TG, PE-P, LPE-O and lyso-glycerophosphocholines (LPC), as well as 34 species (including $22 \mathrm{TGs}$ ) displayed significantly lower levels in females compared to males (Figures S8 and S9, Tables S5 and S6). Within the aged participants, the subclasses PC-O and SM, as well as 26 lipid species (including nine SMs and seven PC-Os), displayed higher levels in females compared to males, while the subclasses TG and DG, as well as 11 species (including ten TGs), showed lower levels in females compared to males (Figures S8 and S9, Tables S5 and S6).

As to the saturation level, a significant and negative association was observed between the MUFA/PUFA ratio for PE-O and the male sex (Figure S4 and Table S7). Post-hoc tests revealed, that this ratio was significantly lower in females compared to males, in young participants only (Figure S10 and Table S8). The PC-O/PE-O ratio was significantly and negatively associated with the male sex (Figure S6 and Table S9). Again, post-hoc tests showed, that this ratio was significantly lower in females compared to males in young participants only (Figure S11 and Table S10).

Concerning the lipid ontology enrichment analysis, $30 \mathrm{LION}$ terms were significantly enriched in young females compared to young males (Figure S12A and Table S13), with "membrane component" being the most enriched LION term (149 matches, $q$-value $\leq 0.0001)$. In the aged participants, $30 \mathrm{LION}$ terms were significantly enriched in females compared to males (Figure S12B and Table S14) with "membrane component" also being the most enriched LION term (149 matches, $q$-value $\leq 0.0001)$.

\section{Discussion}

\subsection{Unravelling Age- and Sex-Associated Lipid Signature}

As all participants of the present study were free of exercise-limiting chronic diseases and fulfilled the WHO recommendations for daily physical activity, the investigated lipidome reflects clinically healthy phenotype [52]. In this way, this work could identify age- and sex-associated differences in the serum lipid profile, avoiding the confounding effects of symptomatic cardiometabolic diseases on lipid metabolism. Thereby, this study confirmed that age strongly determines the composition of the serum lipidome (Figure 2) [35,50]. Strikingly, aged females exhibited higher levels in 138 out of 218 lipid species, representing 15 distinct lipid subclasses, while aged males displayed higher levels in 107 out of 218 species, representing 13 subclasses, compared to their respective younger counterparts (Figure 3). The investigated sex-balanced sample allowed for the identification of these nuances, circumventing the selection bias towards females traditionally found in ageing studies $[32,40,43]$.

\subsection{Cardiometabolic Significance of the Identified Lipid Signature}

As illustrated in the summarising Figure 5, aged participants were characterised by both cardiometabolically favourable and deleterious lipid features. The favourable features might indicate that aged participants benefited from a protective genetic background and/or a lifestyle to reach an advanced age without any excluding medical conditions. Indeed, as age is a major risk factor for most exclusion criteria of the present study, the selection pressure was likely greater on aged compared to young participants. As to the deleterious lipid features, they might be a sign of a beginning age-related metabolic imbalance in otherwise clinically healthy aged humans. 


\section{Cardiometabolically favourable and deleterious lipid species}

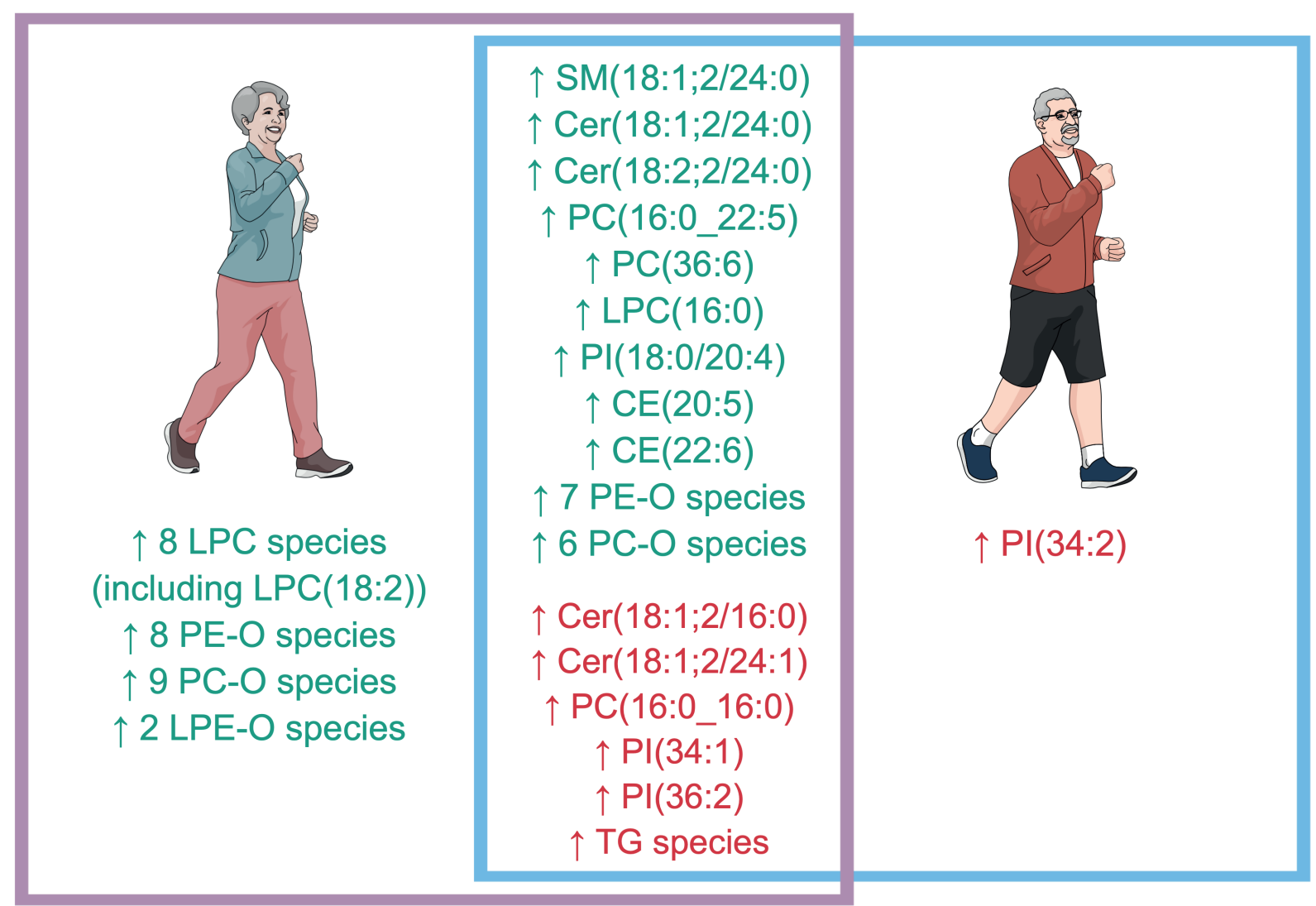

Figure 5. Summary of the main findings. Abbreviations: $\mathrm{SM}=$ sphingomyelins, $\mathrm{Cer}=$ ceramide, $\mathrm{PC}=\mathrm{glycerophos}-$ phocholines, LPC = lyso-glycerophosphocholines, PI = glycerophosphoinositols, CE = cholesterol ester, PE-O = alkylglycerophospoethanolamines, $\mathrm{PC}-\mathrm{O}=$ alkyl-glycerophosphocholines, $\mathrm{LPE}-\mathrm{O}=$ lyso-alkyl-glycerophosphoethanolamines, $\mathrm{TG}=$ triglycerides. Figure 5 was created in the Mind the Graph platform (www.mindthegraph.com (accessed on 15 February 2021)).

\subsubsection{Sphingolipids}

Sphingolipids were highly and positively associated with age, as previously reported [33,59]. SM, which interact with cholesterol to regulate membrane trafficking and intracellular signalling, account for most sphingolipids identified in the present work [60]. As SM become biologically active once transformed into Cer by the enzyme sphingomyelin synthase, it is reasonable to think in terms of Cer when reflecting on SM biological functions $[20,21,61,62]$. In the present study, $\mathrm{SM}(18: 1 ; 2 / 24: 0)$, its biologically active analogue $\operatorname{Cer}(18: 1 ; 2 / 24: 0)$ as well as $\operatorname{Cer}(18: 2 ; 2 / 24: 0)$, which have been previously reported to be cardiometabolically favourable, were found at higher levels in both aged females and males [26,29,63]. Cer(18:2;2/24:0), a sphingolipid species containing a 18:2;2 sphingadiene backbone, has been reported to be negatively associated with insulin resistance, while Cer(18:1;2/24:0) is part of the ceramide-phospholipid score for the prediction of cardiovascular risk [64,65]. Concurrently, the cardiometabolically harmful Cer(18:1;2/16:0) and $\operatorname{Cer}(18: 1 ; 2 / 24: 1)$ also exhibited higher levels in aged individuals of both sexes $[26,29,66,67]$. The fact that structurally closely related ceramide species are associated to distinct metabolic consequences highlights the need for detailed lipid analysis at the molecular species level [26-28]. 


\subsubsection{Glycerophospholipids}

PC species accounted for the majority of glycerophospholipids displaying significantly higher levels in aged participants of both sexes. PCs, located mainly in the outer leaflet of plasma membranes, are intrinsically linked to sphingolipids, as they are required in the de novo synthesis of SM from Cer [68,69]. Clinically, the favourable PC(16:0/22:5) and deleterious PC(16:0/16:0) are part of the ceramide-phospholipid score for the prediction of cardiovascular risk, while $\mathrm{PC}(36: 6)$ has also been reported to be cardiometabolically favourable $[29,63,64]$. In the present work, these three species displayed higher levels within both aged females and males.

LPC, which can be generated through the breakdown of PC by phospholipases A2 and glycoprotein lecithin cholesterol acyltransferases, are considered to be the bioactive forms of PC [70]. LPC are believed to be metabolically favourable as they were shown to slowdown cholesterol synthesis and atherogenesis in macrophages [71]. In the present study, 14 LPC species exhibited higher levels with age in females, while only six LPC species showed higher levels with age in males. Specifically, LPC(16:0), which was found to be inversely associated with the incidence of cardiovascular diseases and intima-media thickness, displayed higher levels in both aged females and males [72]. Conversely, LPC(18:2), which has been negatively associated with type 2 diabetes and impaired glucose tolerance, showed higher levels with age in females only [73]. The sex-specific age-related accumulation of LPC species could be a sign of a more favourable lipid signature in aged females.

Conversely to PC, PE are mainly located in the outer leaflet of plasma membrane and in the mitochondrial inner membrane [74]. The ratio PC/PE in plasma and mitochondrial membrane composition has been shown to modulate membrane functions and mitochondrial energy production [74]. Clinically, lower PE abundance in mitochondrial membranes was observed in both Alzheimer's and Parkinson's diseases, while both increased and decreased hepatic PC/PE ratios were associated with non-alcoholic fatty liver disease [75]. In light of these findings, the absence of a significant difference in terms of PC/PE ratio observed between aged and young participants could be a sign of metabolic health. The biological significance of the specific PC-O/PE-O ratio, which was lower in aged compared to young females in the present work, has not yet been explained to the best of the authors' knowledge [74].

PI have long been known as key regulators of cell physiology, yet the importance of their aliphatic chain composition has been only recently recognised [76-78]. PI(18:0/20:4) is the predominant species in healthy mammalian cells, while cancer cells are enriched in PI, totalling 34 and 36 carbon atoms in their aliphatic chains [79,80]. In the present work, aged participants of both sexes displayed higher levels of the presumed healthy PI(18:0/20:4) and unhealthy PI(34:1), PI(36:2) and PI(36:4). In addition, aged males showed higher levels of the presumed unhealthy PI(34:2). Again, this might be a sign for a more favourable age-related evolution of the circulating lipidome composition in females.

PC-O, PE-O and LPE-O belong to ether-glycerophospholipids [81]. In the present work, 15 PE-O, 15 PC-O and two LPE-O displayed higher levels in aged females, while only seven PE-O and six PC-O were more abundant with age in males. These results are concordant with the ones of the lipid ontology analysis, showing that the LION term "1-alkyl,2-acylglycerophosphoethanolamines" (PE-O) was enriched with age in females only (Figure 4). These sex-specific age-related differences in ether-glycerophospholipid species could once more indicate a favourable age-related evolution of the lipidome composition in females. Indeed, ethers-glycerophospholipids act, amongst others, as cellular antioxidants $[81,82]$. This function is closely related to peroxisomes, where they are synthesised [81]. Two lethal diseases in childhood caused by inherited deficiencies in ether-glycerophospholipid, rhizomelic chondrodysplasia punctate and Zellweger spectrum disorders, highlight the importance of ether-glycerophospholipids to human health [81]. Lower circulating levels of ether-glycerophospholipids have also been observed in patients with non-alcoholic steatohepatitis and children with type 1 diabetes [83,84]. The fact that PE-O, LPE-O and LPE are synthesised in the inner membrane of mitochondria may explain 
why the LION term "mitochondrion" was enriched within aged females only in the lipid ontology analysis [85]. Lastly, the terms "plasma membrane" and "membrane composition" were enriched with age in both females and males, which implies that membrane composition changes with age.

\subsubsection{Cholesterol Esters, Glycerolipids and Saturation Levels}

The cardiometabolically favourable $\mathrm{CE}(22: 6)$ and $\mathrm{CE}(20: 5)$ showed higher levels in both aged females and males. Circulating $\mathrm{CE}$ levels have been shown to be negatively associated with cardiovascular diseases [86,87]. The acyl chains 22:6 and 20:5 likely correspond to docosahexaenoate and eicosapentaenoate, circulating levels of which are negatively associated with fatal coronary heart diseases [88,89]. Additionally, serum level of CE(22:6) has been reported to be significantly lower in patients with Alzheimer's disease compared to cognitively healthy subjects, with lower levels of $\mathrm{CE}(22: 6)$ corresponding to more severe dementia [90].

Ten and seven TG species displayed higher levels in aged females and males, respectively. In addition, most TG species exhibited lower levels in females compared to males (Figure S8), yet the number decreased after menopause as previously described [59,91]. While both the European Society of Cardiology and the American Heart Association consider TG as important biomarkers of cardiovascular diseases due to their association with circulating apolipoproteins B, it is not clear yet if TG are directly atherogenic [10,92]. Nevertheless, the elevated TGs levels likely indicate a beginning age-related impairment in lipid metabolism in otherwise healthy aged humans.

Finally, the absence of significant differences in MUFA/PUFA ratios between young and aged individuals in all subclasses but PI, LPE and Cer could be interpreted as a persistence of the protection against oxidative stress. Indeed, a low degree of fatty acid unsaturation in membranes and plasma has been linked with longevity [39,93-95]. The reason for this is that fewer unsaturated fatty acids are less susceptible to lipid peroxidation, which leads to less oxidation-mediated damage to macromolecules $[39,96]$. The metabolic significance of the MUFA/PUFA differences observed for the specific subclasses PI, LPE and Cer are not known to the best of the authors' knowledge.

\subsection{Moving Away from Subclass towards Species Analysis in Clinical Medicine}

In clinical practice, lipid measurements are still often limited to HDL-C, LDL-C, total cholesterol and triglycerides. Although these parameters have been proven effective in evaluating cardiovascular risk, recent data demonstrated that specific ceramide species predict cardiovascular risk beyond them, calling for detailed lipid analysis at the molecular species level $[10,26,29,92]$. The results of the present study support this call considering that, in several cases, associations could be observed once zooming into species diversity within the same lipid subclass. For instance, no significant difference was observed for $\mathrm{CE}$ as a subclass between aged and young participants, while both $\mathrm{CE}(22: 6)$ and $\mathrm{CE}(20: 5)$ displayed significantly higher levels in aged compared to young participants. Different species within the same subclass have distinct biological roles, as illustrated by the cardiometabolic favourable and deleterious ceramide species [26-28,65]. Undoubtedly, lipidomic studies will provide new biomarkers to improve patients' stratification and follow-up of patients suffering from cardiometabolic diseases [12].

\subsection{Limitations}

This study should be assessed in light of its limitations. First, investigating serum lipids does not provide information about their cellular origin, destination or subcellular localisation. Thus, the findings should be interpreted with caution, when it comes to mechanistic explanations. As this is an inherent limitation of cross-sectional populationbased studies, the present results should be seen as a starting point for both prospective intervention and fundamental studies. Second, the cross-sectional nature of this study allows only for the establishment of associations, and not causality, between clinical and 
lipid phenotypes [97]. However, in light of the practical hurdles to conducting longitudinal studies over the lifespan, cross-sectional studies represent acceptable alternatives. Next, the biological significance of many lipid species is far from being understood, which prevents a comprehensive interpretation of the serum lipidome. Specifically, little or no data are available on the biological roles of GSL, LPE and LPI species [98-102]. In addition, the differences in lipid annotation levels also complicate data interpretation. For instance, many SM species were identified on the hydroxyl group level only, making a reflection in terms of Cer species difficult [103]. Another limitation is the fact that the biological insights provided by LION/web, the very first lipid ontology enrichment tool, are currently limited to associations between lipid species, physicochemical properties, general biological functions and organelles. Lastly, all participants lived in a small geographic area in Switzerland; therefore, results might not be generalisable to populations living in different regions of the world.

\section{Materials and Methods}

\subsection{Participants}

The investigated subset consisted of 73 young ( $25.2 \pm 2.6$ years, $43 \%$ female) and 77 aged (73.5 \pm 2.3 years, $48 \%$ female) individuals. As reported in the study protocol, only healthy participants from the Basel area (Switzerland), who did not have exerciselimiting chronic disease, were non-smokers, or quit at least ten years ago, were included in the COmPLETE-Health study [54]. This excluded participants with a history of coronary artery disease, stroke, heart failure, lower-extremity artery disease, any kind of malignant tumour, diabetes, obesity, clinically apparent kidney failure, severe liver disease, chronic obstructive pulmonary disease GOLD stages two to four, arterial hypertension grades two and three, drug or alcohol abuse, exercise-limiting osteoporosis or orthopaedic conditions and clinically manifest Alzheimer's disease or dementia. The study was conducted in accordance with the Declaration of Helsinki, approved by the Ethics Committee of NorthWestern and Central Switzerland (EKNZ 2017-01451) and registered on ClinicalTrials.gov (NCT03986892). All participants provided written informed consent.

\subsection{Data Collection}

Data were collected between January 2018 and June 2019. Prior to the clinical examination, participants were instructed not to diverge from habitual eating behaviour (for the previous $72 \mathrm{~h}$ ), and to avoid exercising, drinking alcohol (for the previous $24 \mathrm{~h}$ ) and drinking caffeinated beverages (for the previous $4 \mathrm{~h}$ ). Participants were randomised in five time slots (08:00, 10:00, 12:00, 14:00 and 16:00) and measurements took approximately four hours each. After an hour of measurements at rest, trained medical staff collected blood samples in fasted state (at least three hours) by venepuncture of the cubital fossa $\left(2 \times 7.5 \mathrm{~mL}\right.$ serum-gel, Monovette ${ }^{\circledR}$, Sarstedt, Nümbrecht, Germany). Serum samples were gently shaken for $30 \mathrm{~min}$, centrifuged $\left(3000 \mathrm{rpm} ; 10 \mathrm{~min} ; 20-23^{\circ} \mathrm{C}\right)$, aliquoted and frozen at $-80^{\circ} \mathrm{C}$.

Smoking status was assessed by telephone interview prior to the examination, while physicians reviewed medical history and medications by questionnaires on site. Body fat content was quantified using a four-segment bioelectrical impedance analysis (Inbody 720, Inbody Co. Ltd., Seoul, Korea). Physical activity was objectively monitored over the 14 consecutive days following the clinical examination using a wrist-worn triaxial accelerometer (GeneActive Activinsights Ltd., Kimbolton, UK). Data were analysed using the validated open-source Excel macro file "General physical activity" (version 2), quantifying total and moderate-to-vigorous physical activity in minutes per day (moderate defined as 4.00-6.99 Metabolic Equivalent of Task (METS) and vigorous $\geq 7$ METS) [104]. The recruitment and data collection processes have been previously described in detail in the study protocol [54]. 


\subsection{Biochemical Analysis}

Total cholesterol, LDL-C, HDL-C and triglyceride concentrations were analysed from serum using an Olympus AU680 automatic analyser (Beckman Coulter, Brea, CA, USA), enzymatic reagents (DiaSys, Holzheim, Germany) and secondary standards (Roche Diagnostics, Mannheim, Germany). HbA1c was quantified from whole blood by high-pressure liquid chromatography using D-10 (Bio-Rad, Hercules, CA, USA).

\subsection{Lipid Extraction}

Lipids were extracted by the addition of $200 \mu \mathrm{L}$ of Butanol/Methanol (1:1) solution to $40 \mu \mathrm{L}$ of serum. Following the centrifugation for $15 \mathrm{~min}$ at $4000 \times \mathrm{g}$ at $4{ }^{\circ} \mathrm{C}$, the resulting supernatants were collected and transferred to liquid chromatography-mass spectrometry (LC-MS) vials for injection $[105,106]$.

\subsection{Untargeted Lipidomics}

Serum lipid extracts were analysed by reversed-phase liquid chromatography coupled to a high-resolution mass spectrometry (RPLC-HRMS) instrument (Agilent 6550 iFunnel Q-TOF LC/MS, Agilent Technologies, Santa Clara, CA, USA) [107,108]. In both positive and negative ionisation mode, the chromatographic separation was carried out on a Zorbax Eclipse Plus C18 (1.8 $\mu \mathrm{m}, 100 \mathrm{~mm} \times 2.1 \mathrm{~mm}$ I.D. column) (Agilent Technologies, Santa Clara, CA, USA). Mobile phase was composed of $A=60: 40(v / v)$ Acetonitrile:water with $10 \mathrm{mM}$ ammonium acetate and $0.1 \%$ acetic acid and $\mathrm{B}=88: 10: 2$ Isopropanol:acetonitrile:water with $10 \mathrm{mM}$ ammonium acetate and $0.1 \%$ acetic acid. The flow rate was $600 \mu \mathrm{L} / \mathrm{min}$, column temperature $60^{\circ} \mathrm{C}$ and sample injection volume $2 \mu \mathrm{L}$. Electrospray ionisation source conditions were set as follows: dry gas temperature $200^{\circ} \mathrm{C}$, nebuliser $35 \mathrm{psi}$ and flow $14 \mathrm{~L} / \mathrm{min}$, sheath gas temperature $300{ }^{\circ} \mathrm{C}$ and flow $11 \mathrm{~L} / \mathrm{min}$, nozzle voltage $1000 \mathrm{~V}$, and capillary voltage +/ $-3500 \mathrm{~V}$. Full scan acquisition mode in the range of 100-1700 mass-to-charge ratio $(\mathrm{m} / \mathrm{z})$ was applied for data acquisition while iterative tandem mass spectrometry (MS/MS) data-dependent acquisition at $25 \mathrm{eV}$ was used to acquire the MS/MS data on pooled quality control (QC) samples. Iterative MS/MS was performed in five consecutive injections using computer-driven exclusion. The scan rate was set to three spectra/s with a duration of $333.3 \mathrm{~ms} / \mathrm{spectrum}$ and a narrow isolation width of $1.3 \mathrm{~m} / \mathrm{z}$. The mass error tolerance was $+/-20 \mathrm{ppm}$ with a retention time exclusion tolerance of $+/-0.1 \mathrm{~min}$. Precursor ions were excluded after two spectra, with a maximum of three precursors per cycle. The precursor threshold was set to an absolute threshold of 5000 counts in positive mode and 2500 counts in negative mode.

\subsection{Quality Control}

Pooled QC samples (representative of the entire sample set) were analysed every ten samples throughout the overall analytical run in order to assess the quality of the data, correct the signal intensity drift and remove the peaks with poor reproducibility $(\mathrm{CV}>20 \%)[109,110]$. In addition, a series of diluted quality controls (dQC) were prepared by dilution with buthanol:methanol (1:1): $100 \% \mathrm{QC}, 50 \% \mathrm{QC}, 25 \% \mathrm{QC}, 12.5 \% \mathrm{QC}$ and $6.25 \% \mathrm{QC}$ and analysed at the beginning and at the end of the sample batch. This dQC series served as a filter to remove the features, for which MS signal response was not linear (correlation with dilution factor $<0.8$ ) [111].

\subsection{Data Processing and Lipid Annotation}

Raw RPLC-HRMS(/MS) data were deconvoluted using MS-DIAL version 4.00 and lipids were annotated by matching accurate mass, isotope ratio and MS/MS spectra with the LipidBlast library on 29 November 2019 [107,112]. Relative quantification of lipids was based on extracted ion chromatogram areas for the monitored precursor ions at the MS level. The obtained tables (containing peak areas of detected and annotated lipids by MS and MS/MS and MS only) were exported to an R-based in-house developed application, where the signal intensity drift over time was corrected using the locally estimated smoothing 
function (LOESS) and the cubic spline algorithm, followed by analytical variability filter (CV (QC features) $>20 \%$ ) and visual inspection of linear response [109,110]. Redundancies were then removed. Finally, lipids identified on MS level only were targeted to obtain an MS/MS match.

\subsection{Lipid Shorthand Notation}

Using the LipidLynxX Converter tool, lipid shorthand notation issued from MSDIAL was converted to the community-accepted shorthand notation system introduced by Liebisch et al. $[103,113]$. Two authors (J.C. and H.G.-A.) manually double-checked the shorthand notation of each lipid species.

\subsection{Statistical Analysis}

Each lipid species was assigned its corresponding lipid subclass, according to the LIPID MAPS ${ }^{\circledR}$ Lipid Classification System, and saturation level of their aliphatic chains (saturated fatty acid, MUFA or PUFA) [114]. Lipid species abundances were summed to obtain abundances for each lipid subclass and saturation level. Abundances were $\log _{2}-$ transformed prior to statistical analysis. MUFA to PUFA and PC to PE ratios were calculated on subclass levels, if applicable. Unless otherwise specified, all statistical analyses were conducted on the species and subclass levels as well as on MUFA to PUFA and PC to PE ratios.

To investigate global age-related differences in lipid species, unsupervised and supervised analyses were carried out using BIOMEX version 1.0-3, a novel web-based bioinformatic tool designed to facilitate the Biological Interpretation Of Multi-omics Experiments [115]. Specifically, dimensionality reduction was conducted using PCA, while differential analysis was computed using the linear limma model adjusted for blood sampling time [116].

Multiple linear regressions were run to assess associations between lipids, age, sex and the interaction between age and sex, while adjusting for the following previously described clinical confounders: body fat (\%), statins intake, HbA1c (\%), daily total physical activity (min), blood sampling time and fasting time prior to blood sampling [117-125]. Lipids were used as dependent variables, while the other parameters served as independent variables. Continuous dependent and independent variables were z-standardised prior to calculation [126]. Post-hoc tests, using the emmeans R-package (version 1.4.8), were calculated to determine and compare the estimated marginal means of each lipid in aged and young participants within both sexes [57]. The same was done for females and males in both age groups. Resulting $\beta$ coefficients were converted to percentage of difference for ease of interpretation $[57,127]$.

$$
\text { Percentage of difference }=\left(2^{\beta}-1\right) \times 100
$$

Finally, lipid species were ordered by decreasing percentage of differences for all four age and sex groups. Resulting lists were entered into a lipid ontology enrichment tool (LION/web, version 2020.07.14), a web application developed to perform network analysis within complex lipidomic datasets in order to bridge the gap between data generated by lipidomic assays and their implication in cellular metabolism [58].

Normality of the residuals was checked graphically prior to running the abovementioned statistical tests. For each statistical test, all $p$-values were adjusted together using the Benjamini-Hochberg method [128]. BIOMEX also uses the Benjamini-Hochberg method, while LION/web uses the q-value method to adjust $p$-values [58,115]. Adjusted $p$-values $\leq 0.05$ were considered significant. Unless otherwise specified, statistical analyses were carried out using $\mathrm{R}$ (version 4.0.2) [129]. Rain plots were computed using a previously published R-code [130]. 


\section{Conclusions}

This study provides a comprehensive serum lipid profiling of clinically healthy humans in their twenties and seventies, allowing for the identification of age- and sexassociated lipid species. Age was identified as the major determinant of the circulating lipidome composition. Compared to the younger individuals, aged females and males exhibited significantly higher levels of sphingolipid, glycerophospholipid, cholesterol ester and triglyceride species. In particular, they showed higher levels in specific SM, Cer, PC, LPC, PI and CE species previously described as cardiometabolically favourable. These favourable features might indicate that aged participants benefited from protective genetic, environmental or lifestyle factors to reach their age in good health. Simultaneously, elevated levels of deleterious Cer, PC, PI and TGs species were also observed within the aged participants. This could sign a beginning age-related impairment in lipid metabolism. Remarkably, aged females were characterised by higher levels in several ether-glycerophospholipid and LPC species, which might support a potentially healthier age-related evolution of the lipidome composition within females. Finally, lipid species analysis revealed findings not captured by subclass analysis. This highlights the necessity to implement detailed lipid investigation at the molecular species level in clinical research studies in order to improve patients' stratification and healthspan extension strategies.

Supplementary Materials: The following are available online at https:/ / www.mdpi.com/article/10 .3390 / metabo11050287/s1, Figure S1 Distribution of clinical data by age and sex, Figure S2 Lipid subclasses: percentage of difference in the aged compared to the young, Figure S3 Distribution of lipid subclasses by age and sex, Figure S4 Associations between lipid saturation, age, sex and clinical variables, Figure S5 Saturation level: percentage of difference in the aged compared to the young, Figure S6 Associations between PC/PE ratios, age, sex and clinical variables, Figure S7 PC/PE ratios: percentage of difference in the aged compared to the young, Figure S8 Lipid subclasses: percentage of difference in females compared to males, Figure S9 Lipid species: percentage of difference in females compared to males, Figure S10 Saturation level: percentage of difference in females compared to males, Figure S11 PC/PE ratios: percentage of difference in females compared to males, Figure S12 LION enrichment analysis: females compared to males, Table S1 Principal component analysis highlighting the difference in lipid profile between young and aged participants, Table S2 Differential analysis highlighting lipid species displaying significant higher levels in the aged compared to the young participants, Table S3 Multiple linear regressions on the subclass level, Table S4 Multiple linear regressions on the species level, Table S5 Post-hoc tests on the subclass level, Table S6 Post-hoc tests on the species level, Table S7 Multiple linear regressions regarding the MUFA/PUFA ratios, Table S8 Post-hoc tests regarding the MUFA/PUFA ratios, Table S9 Multiple linear regressions regarding the PC/PE ratios, Table S10 Post-hoc tests regarding the PC/PE ratios, Table S11 LION enrichment analysis, age difference within females, Table S12 LION enrichment analysis, age difference within males, Table S13 LION enrichment analysis, sex difference within young, Table S14 LION enrichment analysis, sex difference within aged, Table S15 Lipidomics and clinical dataset, Supplementary figures' and tables' captions.

Author Contributions: Conceptualization, J.C., H.G.-A., D.I., J.W., R.K., K.K., T.H., H.H., J.I. and A.S.-T.; methodology, J.C., H.G.-A., J.W., R.K., L.S., T.H., H.H., J.I. and A.S.-T.; software, J.C. and D.I.; validation, J.C., H.G.-A., T.T. and J.I.; formal analysis, J.C., H.G.-A., D.I., F.C. and J.I.; investigation, J.C., H.G.-A., T.T., J.W., R.K., L.S., K.K., T.H. and J.I.; resources, J.C., H.G.-A., J.I. and A.S.-T.; data curation, J.C., H.G.-A., T.T., J.W. and R.K.; writing—original draft preparation, J.C.; writing-review and editing, J.C., H.G.-A., D.I., T.T., J.W., R.K., F.C., L.S., K.K., T.H., H.H., J.I. and A.S.-T.; visualization, J.C., D.I., F.C. and J.I.; supervision, H.G.-A., J.I. and A.S.-T.; project administration, J.C., H.G.-A., J.W., R.K. and J.I.; funding acquisition, A.S.-T. All authors have read and agreed to the published version of the manuscript.

Funding: This study was funded by the Swiss National Science Foundation (grant no. 182815 to Arno Schmidt-Trucksäss and 316030_183377 to Julijana Ivanisevic). This work was also supported by funds from Faculty of Biology and Medicine (FBM), University of Lausanne (UNIL). 
Institutional Review Board Statement: The study was conducted according to the guidelines of the Declaration of Helsinki, approved by the Ethics Committee of North-Western and Central Switzerland on October 172017 (EKNZ 2017-01451) and registered on ClinicalTrials.gov (NCT03986892).

Informed Consent Statement: Informed consent was obtained from all subjects involved in the study.

Data Availability Statement: All data presented in this study are available within the article and supplementary material.

Acknowledgments: We thank Caren Mutschmann (Synlab Analytics, Berlin, Germany) and Winfried März (Synlab Academy, Mannheim, Germany) for the quantification of $\mathrm{HbA1c}$ in the serum samples. We thank Hubert Scharnagl (Clinical Institute of Medical and Chemical Laboratory Diagnostics, Medical University of Graz, Austria) for the analysis of cholesterol and triglycerides in the blood samples. We are grateful to Christopher Klenk, Gilles Nève and to all the Bachelor and Master students (Department of Sport, Exercise and Health, University of Basel, Switzerland) who contributed to the collection of data. We thank Philip Zeuschner (Department of Urology and Pediatric Urology, University of Saarland, Germany) for his precious advice. Finally, we acknowledge the use of the Mind the Graph platform (www.mindthegraph.com (accessed on 15 July 2020)) to create the graphical abstract and the Figure 5.

Conflicts of Interest: The authors declare no conflict of interest. The funders had no role in the design of the study; in the collection, analyses, or interpretation of data; in the writing of the manuscript, or in the decision to publish the results.

\section{References}

1. $\quad$ Beard, J.R.; Officer, A.; de Carvalho, I.A.; Sadana, R.; Pot, A.M.; Michel, J.P.; Lloyd-Sherlock, P.; Epping-Jordan, J.E.; Peeters, G.; Mahanani, W.R.; et al. The World report on ageing and health: A policy framework for healthy ageing. Lancet 2016, 387, $2145-2154$. [CrossRef]

2. Seals, D.R.; Justice, J.N.; LaRocca, T.J. Physiological geroscience: Targeting function to increase healthspan and achieve optimal longevity. J. Physiol. 2016, 594, 2001-2024. [CrossRef]

3. Nikolich-Žugich, J.; Goldman, D.P.; Cohen, P.R.; Cortese, D.; Fontana, L.; Kennedy, B.K.; Mohler, M.J.; Olshansky, S.J.; Perls, T.; Perry, D.; et al. Preparing for an Aging World: Engaging Biogerontologists, Geriatricians, and the Society. J. Gerontol. Ser. Abiological. Sci. Med. Sci. 2015, 71, 435-444. [CrossRef] [PubMed]

4. Crimmins, E.M. Lifespan and Healthspan: Past, Present, and Promise. Gerontologist 2015, 55, 901-911. [CrossRef]

5. Chang, A.Y.; Skirbekk, V.F.; Tyrovolas, S.; Kassebaum, N.J.; Dieleman, J.L. Measuring population ageing: An analysis of the Global Burden of Disease Study 2017. Lancet Public Health 2019, 4, e159-e167. [CrossRef]

6. Kaeberlein, M.; Rabinovitch, P.S.; Martin, G.M. Healthy aging: The ultimate preventative medicine. Science 2015, 350, 1191-1193. [CrossRef] [PubMed]

7. Bloom, D.E.; Chatterji, S.; Kowal, P.; Lloyd-Sherlock, P.; McKee, M.; Rechel, B.; Rosenberg, L.; Smith, J.P. Macroeconomic implications of population ageing and selected policy responses. Lancet 2015, 385, 649-657. [CrossRef]

8. Suhre, K.; Shin, S.Y.; Petersen, A.K.; Mohney, R.P.; Meredith, D.; Wägele, B.; Altmaier, E.; Deloukas, P.; Erdmann, J.; Grundberg, E.; et al. Human metabolic individuality in biomedical and pharmaceutical research. Nature 2011, 477, 54-60. [CrossRef] [PubMed]

9. Després, J.-P. Predicting longevity using metabolomics: A novel tool for precision lifestyle medicine? Nat. Rev. Cardiol. 2020, 17, 67-68. [CrossRef]

10. Mach, F.; Baigent, C.; Catapano, A.L.; Koskinas, K.C.; Casula, M.; Badimon, L.; Chapman, M.J.; De Backer, G.G.; Delgado, V.; Ference, B.A.; et al. 2019 ESC/EAS Guidelines for the management of dyslipidaemias: Lipid modification to reduce cardiovascular risk: The Task Force for the management of dyslipidaemias of the European Society of Cardiology (ESC) and European Atherosclerosis Society (EAS). Eur. Heart J. 2019, 41, 111-188. [CrossRef]

11. Morrison, L.M.; Hall, L.; Chaney, A.L. Cholesterol metabolism and its relationship to atherosclerosis, coronary artery disease, and arteriosclerosis. Am. J. Med. 1948, 4, 616. [CrossRef]

12. Quehenberger, O.; Dennis, E.A. The Human Plasma Lipidome. N. Engl. J. Med. 2011, 365, 1812-1823. [CrossRef] [PubMed]

13. Wang, M.; Wang, C.; Han, R.H.; Han, X. Novel advances in shotgun lipidomics for biology and medicine. Prog. Lipid. Res. 2016, 61, 83-108. [CrossRef]

14. Yang, K.; Han, X. Lipidomics: Techniques, Applications, and Outcomes Related to Biomedical Sciences. Trends Biochem. Sci. 2016, 41, 954-969. [CrossRef] [PubMed]

15. Lydic, T.A.; Goo, Y.-H. Lipidomics unveils the complexity of the lipidome in metabolic diseases. Clin. Transl. Med. 2018, 7, e4. [CrossRef]

16. de Diego, I.; Peleg, S.; Fuchs, B. The role of lipids in aging-related metabolic changes. Chem. Phys. Lipids 2019, 222, 59-69. [CrossRef]

17. Maxfield, F.R.; Tabas, I. Role of cholesterol and lipid organization in disease. Nature 2005, 438, 612-621. [CrossRef] 
18. Arish, M.; Husein, A.; Kashif, M.; Sandhu, P.; Hasnain, S.E.; Akhter, Y.; Rub, A. Orchestration of membrane receptor signaling by membrane lipids. Biochimie 2015, 113, 111-124. [CrossRef] [PubMed]

19. Meer, G.v.; Sprong, H. Membrane lipids and vesicular traffic. Curr. Opin. Cell Biol. 2004, 16, 373-378. [CrossRef]

20. Hannun, Y.A.; Obeid, L.M. Principles of bioactive lipid signalling: Lessons from sphingolipids. Nat. Rev. Mol. Cell Biol. 2008, 9, 139-150. [CrossRef] [PubMed]

21. Hannun, Y.A.; Obeid, L.M. Sphingolipids and their metabolism in physiology and disease. Nat. Rev. Mol. Cell Biol. 2018, 19, 175-191. [CrossRef] [PubMed]

22. Iqbal, J.; Walsh, M.T.; Hammad, S.M.; Hussain, M.M. Sphingolipids and Lipoproteins in Health and Metabolic Disorders. Trends Endocrinol. Metab. 2017, 28, 506-518. [CrossRef]

23. Li, W.; Yang, X.; Xing, S.; Bian, F.; Yao, W.; Bai, X.; Zheng, T.; Wu, G.; Jin, S. Endogenous ceramide contributes to the transcytosis of oxLDL across endothelial cells and promotes its subendothelial retention in vascular wall. Oxidative. Med. Cell. Longev. 2014, 2014, 823071. [CrossRef] [PubMed]

24. Zhang, X.; Zhang, Y.; Wang, P.; Zhang, S.-Y.; Dong, Y.; Zeng, G.; Yan, Y.; Sun, L.; Wu, Q.; Liu, H.; et al. Adipocyte HypoxiaInducible Factor $2 \alpha$ Suppresses Atherosclerosis by Promoting Adipose Ceramide Catabolism. Cell Metab. 2019, 30, 937-951.e935. [CrossRef] [PubMed]

25. Chaurasia, B.; Summers, S.A. Ceramides-Lipotoxic Inducers of Metabolic Disorders. Trends Endocrinol. Metab. 2015, 26, 538-550. [CrossRef] [PubMed]

26. Laaksonen, R.; Ekroos, K.; Sysi-Aho, M.; Hilvo, M.; Vihervaara, T.; Kauhanen, D.; Suoniemi, M.; Hurme, R.; Marz, W.; Scharnagl, H.; et al. Plasma ceramides predict cardiovascular death in patients with stable coronary artery disease and acute coronary syndromes beyond LDL-cholesterol. Eur. Heart J. 2016, 37, 1967-1976. [CrossRef]

27. Havulinna, A.S.; Sysi-Aho, M.; Hilvo, M.; Kauhanen, D.; Hurme, R.; Ekroos, K.; Salomaa, V.; Laaksonen, R. Circulating Ceramides Predict Cardiovascular Outcomes in the Population-Based FINRISK 2002 Cohort. Arter. Thromb. Vasc. Biol. 2016, 36, 2424-2430. [CrossRef]

28. Meeusen, J.W.; Donato, L.J.; Bryant, S.C.; Baudhuin, L.M.; Berger, P.B.; Jaffe, A.S. Plasma Ceramides. Arter. Thromb. Vasc. Biol. 2018, 38, 1933-1939. [CrossRef]

29. Hilvo, M.; Meikle, P.J.; Pedersen, E.R.; Tell, G.S.; Dhar, I.; Brenner, H.; Schöttker, B.; Lääperi, M.; Kauhanen, D.; Koistinen, K.M.; et al. Development and validation of a ceramide- and phospholipid-based cardiovascular risk estimation score for coronary artery disease patients. Eur. Heart J. 2019, 41, 371-380. [CrossRef]

30. Summers, S.A. Could Ceramides Become the New Cholesterol? Cell Metab. 2018, 27, 276-280. [CrossRef]

31. Bustos, V.; Partridge, L. Good Ol' Fat: Links between Lipid Signaling and Longevity. Trends Biochem. Sci. 2017, 42, 812-823. [CrossRef]

32. Jove, M.; Naudi, A.; Gambini, J.; Borras, C.; Cabre, R.; Portero-Otin, M.; Vina, J.; Pamplona, R. A Stress-Resistant Lipidomic Signature Confers Extreme Longevity to Humans. J. Gerontol. Ser. Abiological. Sci. Med. Sci. 2017, 72, 30-37. [CrossRef]

33. Huynh, K.; Barlow, C.K.; Jayawardana, K.S.; Weir, J.M.; Mellett, N.A.; Cinel, M.; Magliano, D.J.; Shaw, J.E.; Drew, B.G.; Meikle, P.J. High-Throughput Plasma Lipidomics: Detailed Mapping of the Associations with Cardiometabolic Risk Factors. Cell Chem. Biol. 2019, 26, 71-84.e74. [CrossRef]

34. Kawanishi, N.; Kato, Y.; Yokozeki, K.; Sawada, S.; Sakurai, R.; Fujiwara, Y.; Shinkai, S.; Goda, N.; Suzuki, K. Effects of aging on serum levels of lipid molecular species as determined by lipidomics analysis in Japanese men and women. Lipids Health Dis. 2018, 17, 135. [CrossRef]

35. Gonzalez-Covarrubias, V.; Beekman, M.; Uh, H.W.; Dane, A.; Troost, J.; Paliukhovich, I.; van der Kloet, F.M.; HouwingDuistermaat, J.; Vreeken, R.J.; Hankemeier, T.; et al. Lipidomics of familial longevity. Aging Cell 2013, 12, 426-434. [CrossRef]

36. Ishikawa, M.; Maekawa, K.; Saito, K.; Senoo, Y.; Urata, M.; Murayama, M.; Tajima, Y.; Kumagai, Y.; Saito, Y. Plasma and Serum Lipidomics of Healthy White Adults Shows Characteristic Profiles by Subjects' Gender and Age. PLoS ONE 2014, 9, e91806. [CrossRef]

37. Wong, M.W.K.; Braidy, N.; Pickford, R.; Vafaee, F.; Crawford, J.; Muenchhoff, J.; Schofield, P.; Attia, J.; Brodaty, H.; Sachdev, P.; et al. Plasma lipidome variation during the second half of the human lifespan is associated with age and sex but minimally with BMI. PLoS ONE 2019, 14, e0214141. [CrossRef]

38. Maekawa, K.; Okemoto, K.; Ishikawa, M.; Tanaka, R.; Kumagai, Y.; Saito, Y. Plasma Lipidomics of Healthy Japanese Adults Reveals Gender- and Age-Related Differences. J. Pharm. Sci. 2017, 106, 2914-2918. [CrossRef]

39. Naudí, A.; Jové, M.; Ayala, V.; Portero-Otín, M.; Barja, G.; Pamplona, R. Membrane lipid unsaturation as physiological adaptation to animal longevity. Front. Physiol. 2013, 4, 372. [CrossRef] [PubMed]

40. Montoliu, I.; Scherer, M.; Beguelin, F.; DaSilva, L.; Mari, D.; Salvioli, S.; Martin, F.P.; Capri, M.; Bucci, L.; Ostan, R.; et al. Serum profiling of healthy aging identifies phospho- and sphingolipid species as markers of human longevity. Aging 2014, 6, 9-25. [CrossRef]

41. Chaleckis, R.; Murakami, I.; Takada, J.; Kondoh, H.; Yanagida, M. Individual variability in human blood metabolites identifies age-related differences. Proc. Natl. Acad. Sci. USA 2016, 113, 4252-4259. [CrossRef]

42. Darst, B.F.; Koscik, R.L.; Hogan, K.J.; Johnson, S.C.; Engelman, C.D. Longitudinal plasma metabolomics of aging and sex. Aging 2019, 11, 1262-1282. [CrossRef] 
43. Collino, S.; Montoliu, I.; Martin, F.-P.J.; Scherer, M.; Mari, D.; Salvioli, S.; Bucci, L.; Ostan, R.; Monti, D.; Biagi, E.; et al. Metabolic Signatures of Extreme Longevity in Northern Italian Centenarians Reveal a Complex Remodeling of Lipids, Amino Acids, and Gut Microbiota Metabolism. PLoS ONE 2013, 8, e56564. [CrossRef]

44. Menni, C.; Kastenmüller, G.; Petersen, A.K.; Bell, J.T.; Psatha, M.; Tsai, P.-C.; Gieger, C.; Schulz, H.; Erte, I.; John, S.; et al. Metabolomic markers reveal novel pathways of ageing and early development in human populations. Int. J. Epidemiol. 2013, 42, 1111-1119. [CrossRef] [PubMed]

45. Cheng, S.; Larson, M.G.; McCabe, E.L.; Murabito, J.M.; Rhee, E.P.; Ho, J.E.; Jacques, P.F.; Ghorbani, A.; Magnusson, M.; Souza, A.L.; et al. Distinct metabolomic signatures are associated with longevity in humans. Nat. Commun. 2015, 6, 6791. [CrossRef] [PubMed]

46. Beyene, H.B.; Olshansky, G.; Smith, A.A.; Giles, C.; Huynh, K.; Cinel, M.; Mellett, N.A.; Cadby, G.; Hung, J.; Hui, J.; et al. High-coverage plasma lipidomics reveals novel sex-specific lipidomic fingerprints of age and BMI: Evidence from two large population cohort studies. PLoS Biol. 2020, 18, e3000870. [CrossRef]

47. Yu, Z.; Zhai, G.; Singmann, P.; He, Y.; Xu, T.; Prehn, C.; Römisch-Margl, W.; Lattka, E.; Gieger, C.; Soranzo, N.; et al. Human serum metabolic profiles are age dependent. Aging Cell 2012, 11, 960-967. [CrossRef]

48. Rist, M.J.; Roth, A.; Frommherz, L.; Weinert, C.H.; Krüger, R.; Merz, B.; Bunzel, D.; Mack, C.; Egert, B.; Bub, A.; et al. Metabolite patterns predicting sex and age in participants of the Karlsruhe Metabolomics and Nutrition (KarMeN) study. PLoS ONE 2017, 12, e0183228. [CrossRef]

49. Dunn, W.B.; Lin, W.; Broadhurst, D.; Begley, P.; Brown, M.; Zelena, E.; Vaughan, A.A.; Halsall, A.; Harding, N.; Knowles, J.D.; et al Molecular phenotyping of a UK population: Defining the human serum metabolome. Metabolomics 2015, 11, 9-26. [CrossRef]

50. Johnson, L.C.; Parker, K.; Aguirre, B.F.; Nemkov, T.G.; D’Alessandro, A.; Johnson, S.A.; Seals, D.R.; Martens, C.R. The plasma metabolome as a predictor of biological aging in humans. GeroScience 2019, 41, 895-906. [CrossRef]

51. Kohl, H.W., 3rd; Craig, C.L.; Lambert, E.V.; Inoue, S.; Alkandari, J.R.; Leetongin, G.; Kahlmeier, S. The pandemic of physical inactivity: Global action for public health. Lancet 2012, 380, 294-305. [CrossRef]

52. Bull, F.C.; Al-Ansari, S.S.; Biddle, S.; Borodulin, K.; Buman, M.P.; Cardon, G.; Carty, C.; Chaput, J.-P.; Chastin, S.; Chou, R.; et al. World Health Organization 2020 guidelines on physical activity and sedentary behaviour. Br. J. Sports Med. 2020, 54, 1451-1462. [CrossRef] [PubMed]

53. Ross, R.; Blair, S.N.; Arena, R.; Church, T.S.; Despres, J.P.; Franklin, B.A.; Haskell, W.L.; Kaminsky, L.A.; Levine, B.D.; Lavie, C.J.; et al. Importance of Assessing Cardiorespiratory Fitness in Clinical Practice: A Case for Fitness as a Clinical Vital Sign: A Scientific Statement From the American Heart Association. Circulation 2016, 134, e653-e699. [CrossRef] [PubMed]

54. Wagner, J.; Knaier, R.; Infanger, D.; Arbeev, K.; Briel, M.; Dieterle, T.; Hanssen, H.; Faude, O.; Roth, R.; Hinrichs, T.; et al. Functional aging in health and heart failure: The COmPLETE Study. BMC Cardiovasc. Disord. 2019, 19, 180. [CrossRef] [PubMed]

55. Williams, B.; Mancia, G.; Spiering, W.; Agabiti Rosei, E.; Azizi, M.; Burnier, M.; Clement, D.L.; Coca, A.; de Simone, G.; Dominiczak, A.; et al. 2018 ESC/ESH Guidelines for the management of arterial hypertension: The Task Force for the management of arterial hypertension of the European Society of Cardiology (ESC) and the European Society of Hypertension (ESH). Eur. Heart J. 2018, 39, 3021-3104. [CrossRef]

56. Cosentino, F.; Grant, P.J.; Aboyans, V.; Bailey, C.J.; Ceriello, A.; Delgado, V.; Federici, M.; Filippatos, G.; Grobbee, D.E.; Hansen, T.B.; et al. 2019 ESC Guidelines on diabetes, pre-diabetes, and cardiovascular diseases developed in collaboration with the EASD: The Task Force for diabetes, pre-diabetes, and cardiovascular diseases of the European Society of Cardiology (ESC) and the European Association for the Study of Diabetes (EASD). Eur. Heart J. 2019, 41, 255-323. [CrossRef]

57. Searle, S.R.; Speed, F.M.; Milliken, G.A. Population Marginal Means in the Linear Model: An Alternative to Least Squares Means. Am. Stat. 1980, 34, 216-221. [CrossRef]

58. Molenaar, M.R.; Jeucken, A.; Wassenaar, T.A.; van de Lest, C.H.A.; Brouwers, J.F.; Helms, J.B. LION/web: A web-based ontology enrichment tool for lipidomic data analysis. GigaScience 2019, 8. [CrossRef] [PubMed]

59. Gonzalez-Covarrubias, V. Lipidomics in longevity and healthy aging. Biogerontology 2013, 14, 663-672. [CrossRef]

60. Endapally, S.; Frias, D.; Grzemska, M.; Gay, A.; Tomchick, D.R.; Radhakrishnan, A. Molecular Discrimination between Two Conformations of Sphingomyelin in Plasma Membranes. Cell 2019, 176, 1040-1053.e1017. [CrossRef]

61. Trayssac, M.; Hannun, Y.A.; Obeid, L.M. Role of sphingolipids in senescence: Implication in aging and age-related diseases. J. Clin. Investig. 2018, 128, 2702-2712. [CrossRef]

62. Ogretmen, B. Sphingolipid metabolism in cancer signalling and therapy. Nat. Rev. Cancer 2018, 18, 33-50. [CrossRef]

63. Sigruener, A.; Kleber, M.E.; Heimerl, S.; Liebisch, G.; Schmitz, G.; Maerz, W. Glycerophospholipid and Sphingolipid Species and Mortality: The Ludwigshafen Risk and Cardiovascular Health (LURIC) Study. PLoS ONE 2014, 9, e85724. [CrossRef]

64. Hilvo, M.; Wallentin, L.; Lakic, T.G.; Held, C.; Kauhanen, D.; Jylhä, A.; Lindbäck, J.; Siegbahn, A.; Granger, C.B.; Koenig, W.; et al. Prediction of Residual Risk by Ceramide-Phospholipid Score in Patients With Stable Coronary Heart Disease on Optimal Medical Therapy. J. Am. Heart Assoc. 2020, 9, e015258. [CrossRef] [PubMed]

65. Chew, W.S.; Torta, F.; Ji, S.; Choi, H.; Begum, H.; Sim, X.; Khoo, C.M.; Khoo, E.Y.H.; Ong, W.Y.; Van Dam, R.M.; et al. Largescale lipidomics identifies associations between plasma sphingolipids and T2DM incidence. JCI Insight 2019, 5. [CrossRef] [PubMed]

66. Mantovani, A.; Dugo, C. Ceramides and risk of major adverse cardiovascular events: A meta-analysis of longitudinal studies. J. Clin. Lipidol. 2020, 14, 176-185. [CrossRef] [PubMed] 
67. Cao, R.; Fang, Z.; Li, S.; Xu, M.; Zhang, J.; Han, D.; Hu, W.; Yan, L.; Wang, Y.; Fan, L.; et al. Circulating Ceramide: A New Cardiometabolic Biomarker in Patients With Comorbid Acute Coronary Syndrome and Type 2 Diabetes Mellitus. Front. Physiol. 2020, 11, 1104. [CrossRef] [PubMed]

68. Castro, B.M.; Prieto, M.; Silva, L.C. Ceramide: A simple sphingolipid with unique biophysical properties. Prog. Lipid Res. 2014, 54, 53-67. [CrossRef] [PubMed]

69. Bolla, J.R.; Agasid, M.T.; Mehmood, S.; Robinson, C.V. Membrane Protein-Lipid Interactions Probed Using Mass Spectrometry. Annu. Rev. Biochem. 2019, 88, 85-111. [CrossRef]

70. Xu, H.; Valenzuela, N.; Fai, S.; Figeys, D.; Bennett, S.A.L. Targeted lipidomics-Advances in profiling lysophosphocholine and platelet-activating factor second messengers. FEBS J. 2013, 280, 5652-5667. [CrossRef] [PubMed]

71. Rozenberg, O.; Shih, D.M.; Aviram, M. Human Serum Paraoxonase 1 Decreases Macrophage Cholesterol Biosynthesis. Arter. Thromb. Vasc. Biol. 2003, 23, 461-467. [CrossRef] [PubMed]

72. Fernandez, C.; Sandin, M.; Sampaio, J.L.; Almgren, P.; Narkiewicz, K.; Hoffmann, M.; Hedner, T.; Wahlstrand, B.; Simons, K.; Shevchenko, A.; et al. Plasma Lipid Composition and Risk of Developing Cardiovascular Disease. PLoS ONE 2013, 8, e71846. [CrossRef]

73. Wang-Sattler, R.; Yu, Z.; Herder, C.; Messias, A.C.; Floegel, A.; He, Y.; Heim, K.; Campillos, M.; Holzapfel, C.; Thorand, B.; et al. Novel biomarkers for pre-diabetes identified by metabolomics. Mol. Syst. Biol. 2012, 8, 615. [CrossRef]

74. van der Veen, J.N.; Kennelly, J.P.; Wan, S.; Vance, J.E.; Vance, D.E.; Jacobs, R.L. The critical role of phosphatidylcholine and phosphatidylethanolamine metabolism in health and disease. Biochim. Et Biophys. Acta (BBA)—Biomembr. 2017, 1859, 1558-1572. [CrossRef] [PubMed]

75. Calzada, E.; Onguka, O.; Claypool, S.M. Chapter Two-Phosphatidylethanolamine Metabolism in Health and Disease. In International Review of Cell and Molecular Biology; Jeon, K.W., Ed.; Academic Press: Cambridge, MA, USA, 2016; Volume 321, pp. $29-88$.

76. Di Paolo, G.; De Camilli, P. Phosphoinositides in cell regulation and membrane dynamics. Nature 2006, 443, 651-657. [CrossRef]

77. Balla, T. Phosphoinositides: Tiny Lipids With Giant Impact on Cell Regulation. Physiol. Rev. 2013, 93, 1019-1137. [CrossRef]

78. Bozelli, J.C., Jr.; Epand, R.M. Specificity of Acyl Chain Composition of Phosphatidylinositols. Proteomics 2019, 19, 1900138. [CrossRef] [PubMed]

79. Naguib, A.; Bencze, G.; Engle, D.D.; Chio, I.I.; Herzka, T.; Watrud, K.; Bencze, S.; Tuveson, D.A.; Pappin, D.J.; Trotman, L.C. P53 Mutations Change Phosphatidylinositol Acyl Chain Composition. Cell Rep. 2015, 10, 8-19. [CrossRef] [PubMed]

80. Soussi, T.; Béroud, C. Assessing TP53 status in human tumours to evaluate clinical outcome. Nat. Rev. Cancer 2001, 1, 233-239. [CrossRef]

81. Dean, J.M.; Lodhi, I.J. Structural and functional roles of ether lipids. Protein Cell 2018, 9, 196-206. [CrossRef]

82. Watschinger, K.; Werner, E.R. Orphan enzymes in ether lipid metabolism. Biochimie 2013, 95, 59-65. [CrossRef]

83. Puri, P.; Wiest, M.M.; Cheung, O.; Mirshahi, F.; Sargeant, C.; Min, H.-K.; Contos, M.J.; Sterling, R.K.; Fuchs, M.; Zhou, H.; et al. The plasma lipidomic signature of nonalcoholic steatohepatitis. Hepatology 2009, 50, 1827-1838. [CrossRef]

84. Oresic, M.; Simell, S.; Sysi-Aho, M.; Nanto-Salonen, K.; Seppänen-Laakso, T.; Parikka, V.; Katajamaa, M.; Hekkala, A.; Mattila, I.; Keskinen, P.; et al. Dysregulation of lipid and amino acid metabolism precedes islet autoimmunity in children who later progress to type 1 diabetes. J. Exp. Med. 2008, 205, 2975-2984. [CrossRef]

85. Tatsuta, T.; Scharwey, M.; Langer, T. Mitochondrial lipid trafficking. Trends Cell Biol. 2014, 24, 44-52. [CrossRef] [PubMed]

86. Toledo, E.; Wang, D.D.; Ruiz-Canela, M.; Clish, C.B.; Razquin, C.; Zheng, Y.; Guasch-Ferré, M.; Hruby, A.; Corella, D.; Gómez-Gracia, E.; et al. Plasma lipidomic profiles and cardiovascular events in a randomized intervention trial with the Mediterranean diet. Am. J. Clin. Nutr. 2017, 106, 973-983. [CrossRef] [PubMed]

87. Gerl, M.J.; Vaz, W.L.C.; Domingues, N.; Klose, C.; Surma, M.A.; Sampaio, J.L.; Almeida, M.S.; Rodrigues, G.; Araújo-Gonçalves, P.; Ferreira, J.; et al. Cholesterol is Inefficiently Converted to Cholesteryl Esters in the Blood of Cardiovascular Disease Patients. Sci. Rep. 2018, 8, 14764. [CrossRef]

88. Del Gobbo, L.C.; Imamura, F.; Aslibekyan, S.; Marklund, M.; Virtanen, J.K.; Wennberg, M.; Yakoob, M.Y.; Chiuve, S.E.; dela Cruz, L.; Frazier-Wood, A.C.; et al. $\omega$-3 Polyunsaturated Fatty Acid Biomarkers and Coronary Heart Disease: Pooling Project of 19 Cohort Studies. JAMA Intern. Med. 2016, 176, 1155-1166. [CrossRef] [PubMed]

89. Aimo, L.; Liechti, R.; Hyka-Nouspikel, N.; Niknejad, A.; Gleizes, A.; Götz, L.; Kuznetsov, D.; David, F.P.A.; van der Goot, F.G.; Riezman, H.; et al. The SwissLipids knowledgebase for lipid biology. Bioinformatics 2015, 31, 2860-2866. [CrossRef]

90. Tully, A.M.; Roche, H.M.; Doyle, R.; Fallon, C.; Bruce, I.; Lawlor, B.; Coakley, D.; Gibney, M.J. Low serum cholesteryl esterdocosahexaenoic acid levels in Alzheimer's disease: A case-control study. Br. J. Nutr. 2003, 89, 483-489. [CrossRef]

91. Sugiyama, M.G.; Agellon, L.B. Sex differences in lipid metabolism and metabolic disease risk. Biochem. Cell Biol. 2012, 90, $124-141$. [CrossRef] [PubMed]

92. Miller, M.; Stone, N.J.; Ballantyne, C.; Bittner, V.; Criqui, M.H.; Ginsberg, H.N.; Goldberg, A.C.; Howard, W.J.; Jacobson, M.S.; Kris-Etherton, P.M.; et al. Triglycerides and Cardiovascular Disease. Circulation 2011, 123, 2292-2333. [CrossRef]

93. Pamplona, R.; Barja, G.; Portero-Otin, M. Membrane fatty acid unsaturation, protection against oxidative stress, and maximum life span: A homeoviscous-longevity adaptation? Ann. N. Y. Acad. Sci. 2002, 959, 475-490. [CrossRef]

94. Hulbert, A.J.; Pamplona, R.; Buffenstein, R.; Buttemer, W.A. Life and death: Metabolic rate, membrane composition, and life span of animals. Physiol. Rev. 2007, 87, 1175-1213. [CrossRef] 
95. Pamplona, R. Membrane phospholipids, lipoxidative damage and molecular integrity: A causal role in aging and longevity. Biochim. Biophys. Acta (BBA) Bioenerg. 2008, 1777, 1249-1262. [CrossRef]

96. Pamplona, R. Advanced lipoxidation end-products. Chem. Biol. Interact. 2011, 192, 14-20. [CrossRef]

97. Chu, S.H.; Huang, M.; Kelly, R.S.; Benedetti, E.; Siddiqui, J.K.; Zeleznik, O.A.; Pereira, A.; Herrington, D.; Wheelock, C.E.; Krumsiek, J.; et al. Integration of Metabolomic and Other Omics Data in Population-Based Study Designs: An Epidemiological Perspective. Metabolites 2019, 9, 117. [CrossRef] [PubMed]

98. Silsirivanit, A.; Phoomak, C.; Teeravirote, K.; Wattanavises, S.; Seubwai, W.; Saengboonmee, C.; Zhan, Z.; Inokuchi, J.I.; Suzuki, A.; Wongkham, S. Overexpression of HexCer and LacCer containing 2-hydroxylated fatty acids in cholangiocarcinoma and the association of the increase of LacCer (d18:1-h23:0) with shorter survival of the patients. Glycoconj. J. 2019, 36, 103-111. [CrossRef] [PubMed]

99. Tanaka, K.; Tamiya-Koizumi, K.; Yamada, M.; Murate, T.; Kannagi, R.; Kyogashima, M. Hypoxia remodels the composition of the constituent ceramide species of HexCer and Hex2Cer with phytosphingosine and hydroxy fatty acids in human colon cancer LS174T cells. Glycoconj. J. 2015, 32, 615-623. [CrossRef] [PubMed]

100. Hernández-Corbacho, M.J.; Jenkins, R.W.; Clarke, C.J.; Hannun, Y.A.; Obeid, L.M.; Snider, A.J.; Siskind, L.J. Accumulation of long-chain glycosphingolipids during aging is prevented by caloric restriction. PLoS ONE 2011, 6, e20411. [CrossRef] [PubMed]

101. Piñeiro, R.; Falasca, M. Lysophosphatidylinositol signalling: New wine from an old bottle. Biochim. Biophys. Acta 2012, 1821, 694-705. [CrossRef] [PubMed]

102. Arifin, S.A.; Falasca, M. Lysophosphatidylinositol Signalling and Metabolic Diseases. Metabolites 2016, 6, 6. [CrossRef]

103. Liebisch, G.; Vizcaíno, J.A.; Köfeler, H.; Trötzmüller, M.; Griffiths, W.J.; Schmitz, G.; Spener, F.; Wakelam, M.J.O. Shorthand notation for lipid structures derived from mass spectrometry. J. Lipid Res. 2013, 54, 1523-1530. [CrossRef] [PubMed]

104. Esliger, D.W.; Rowlands, A.V.; Hurst, T.L.; Catt, M.; Murray, P.; Eston, R.G. Validation of the GENEA Accelerometer. Med. Sci. Sports Exerc. 2011, 43, 1085-1093. [CrossRef] [PubMed]

105. Lofgren, L.; Forsberg, G.B.; Stahlman, M. The BUME method: A new rapid and simple chloroform-free method for total lipid extraction of animal tissue. Sci. Rep. 2016, 6, 27688. [CrossRef] [PubMed]

106. Lofgren, L.; Stahlman, M.; Forsberg, G.B.; Saarinen, S.; Nilsson, R.; Hansson, G.I. The BUME method: A novel automated chloroform-free 96-well total lipid extraction method for blood plasma. J. Lipid Res. 2012, 53, 1690-1700. [CrossRef]

107. Cajka, T.; Fiehn, O. Comprehensive analysis of lipids in biological systems by liquid chromatography-mass spectrometry. Trends Anal. Chem. Trac 2014, 61, 192-206. [CrossRef]

108. Cajka, T.; Fiehn, O. LC-MS-Based Lipidomics and Automated Identification of Lipids Using the LipidBlast In-Silico MS/MS Library. Methods Mol. Biol. 2017, 1609, 149-170. [CrossRef]

109. Broadhurst, D.; Goodacre, R.; Reinke, S.N.; Kuligowski, J.; Wilson, I.D.; Lewis, M.R.; Dunn, W.B. Guidelines and considerations for the use of system suitability and quality control samples in mass spectrometry assays applied in untargeted clinical metabolomic studies. Metabolomics 2018, 14, 72. [CrossRef]

110. Dunn, W.B.; Broadhurst, D.; Begley, P.; Zelena, E.; Francis-McIntyre, S.; Anderson, N.; Brown, M.; Knowles, J.D.; Halsall, A.; Haselden, J.N.; et al. Procedures for large-scale metabolic profiling of serum and plasma using gas chromatography and liquid chromatography coupled to mass spectrometry. Nat. Protoc. 2011, 6, 1060-1083. [CrossRef]

111. Gagnebin, Y.; Tonoli, D.; Lescuyer, P.; Ponte, B.; de Seigneux, S.; Martin, P.Y.; Schappler, J.; Boccard, J.; Rudaz, S. Metabolomic analysis of urine samples by UHPLC-QTOF-MS: Impact of normalization strategies. Anal. Chim. Acta 2017, 955, 27-35. [CrossRef]

112. Tsugawa, H.; Cajka, T.; Kind, T.; Ma, Y.; Higgins, B.; Ikeda, K.; Kanazawa, M.; VanderGheynst, J.; Fiehn, O.; Arita, M. MS-DIAL: Data-independent MS/MS deconvolution for comprehensive metabolome analysis. Nat. Methods 2015, 12, 523-526. [CrossRef]

113. Ni, Z.; Fedorova, M. LipidLynxX: Lipid annotations converter for large scale lipidomics and epilipidomics datasets. bioRxiv 2020. [CrossRef]

114. Fahy, E.; Subramaniam, S.; Murphy, R.C.; Nishijima, M.; Raetz, C.R.; Shimizu, T.; Spener, F.; van Meer, G.; Wakelam, M.J.; Dennis, E.A. Update of the LIPID MAPS comprehensive classification system for lipids. J. Lipid Res. 2009, 50, S9-S14. [CrossRef] [PubMed]

115. Taverna, F.; Goveia, J.; Karakach, T.K.; Khan, S.; Rohlenova, K.; Treps, L.; Subramanian, A.; Schoonjans, L.; Dewerchin, M.; Eelen, G.; et al. BIOMEX: An interactive workflow for (single cell) omics data interpretation and visualization. Nucleic Acids Res. 2020. [CrossRef]

116. Ritchie, M.E.; Phipson, B.; Wu, D.; Hu, Y.; Law, C.W.; Shi, W.; Smyth, G.K. limma powers differential expression analyses for RNA-sequencing and microarray studies. Nucleic Acids Res. 2015, 43, e47. [CrossRef]

117. Gerl, M.J.; Klose, C.; Surma, M.A.; Fernandez, C.; Melander, O.; Männistö, S.; Borodulin, K.; Havulinna, A.S.; Salomaa, V.; Ikonen, E.; et al. Machine learning of human plasma lipidomes for obesity estimation in a large population cohort. PLoS Biol. 2019, 17, e3000443. [CrossRef]

118. Chapman, M.J.; Orsoni, A.; Tan, R.; Mellett, N.A.; Nguyen, A.; Robillard, P.; Giral, P.; Thérond, P.; Meikle, P.J. LDL subclass lipidomics in atherogenic dyslipidemia: Effect of statin therapy on bioactive lipids and dense LDL. J. Lipid Res. 2020, 61, 911-932. [CrossRef]

119. Takeda, H.; Izumi, Y.; Tamura, S.; Koike, T.; Koike, Y.; Shiomi, M.; Bamba, T. Lipid Profiling of Serum and Lipoprotein Fractions in Response to Pitavastatin Using an Animal Model of Familial Hypercholesterolemia. J. Proteome Res. 2020, 19, 1100-1108. [CrossRef] 
120. Lu, J.; Lam, S.M.; Wan, Q.; Shi, L.; Huo, Y.; Chen, L.; Tang, X.; Li, B.; Wu, X.; Peng, K.; et al. High-Coverage Targeted Lipidomics Reveals Novel Serum Lipid Predictors and Lipid Pathway Dysregulation Antecedent to Type 2 Diabetes Onset in Normoglycemic Chinese Adults. Diabetes Care 2019, 42, 2117-2126. [CrossRef]

121. Pino, M.F.; Stephens, N.A.; Eroshkin, A.M.; Yi, F.; Hodges, A.; Cornnell, H.H.; Pratley, R.E.; Smith, S.R.; Wang, M.; Han, X.; et al. Endurance training remodels skeletal muscle phospholipid composition and increases intrinsic mitochondrial respiration in men with Type 2 diabetes. Physiol. Genom. 2019, 51, 586-595. [CrossRef] [PubMed]

122. Fikenzer, K.; Fikenzer, S.; Laufs, U.; Werner, C. Effects of endurance training on serum lipids. Vasc. Pharm. 2018, 101, 9-20. [CrossRef]

123. Chua, E.C.; Shui, G.; Lee, I.T.; Lau, P.; Tan, L.C.; Yeo, S.C.; Lam, B.D.; Bulchand, S.; Summers, S.A.; Puvanendran, K.; et al. Extensive diversity in circadian regulation of plasma lipids and evidence for different circadian metabolic phenotypes in humans. Proc. Natl. Acad. Sci. USA 2013, 110, 14468-14473. [CrossRef] [PubMed]

124. Gooley, J.J. Circadian regulation of lipid metabolism. Proc. Nutr. Soc. 2016, 75, 440-450. [CrossRef] [PubMed]

125. Hyötyläinen, T.; Orešič, M. Optimizing the lipidomics workflow for clinical studies-Practical considerations. Anal. Bioanal. Chem. 2015, 407, 4973-4993. [CrossRef]

126. Schielzeth, H. Simple means to improve the interpretability of regression coefficients. Methods Ecol. Evol. 2010, 1, 103-113. [CrossRef]

127. Introduction to SAS. UCLA: Statistical Consulting Group. Available online: https://stats.idre.ucla.edu/other/mult$\mathrm{pkg} / \mathrm{faq} /$ general/faqhow-do-i-interpret-a-regression-model-when-some-variables-are-log-transformed/ (accessed on 16 September 2020).

128. Benjamini, Y.; Hochberg, Y. Controlling the False Discovery Rate: A Practical and Powerful Approach to Multiple Testing. J. R. Stat. Soc. Ser. B 1995, 57, 289-300. [CrossRef]

129. R Core Team. R: A Language and Environment for Statistical Computing; R Foundation for Statistical Computing: Vienna, Austria, 2020; Available online: https:/ / www.R-project.org/ (accessed on 1 April 2020).

130. Henglin, M.; Niiranen, T.; Watrous, J.D.; Lagerborg, K.A.; Antonelli, J.; Claggett, B.L.; Demosthenes, E.J.; von Jeinsen, B.; Demler, O.; Vasan, R.S.; et al. A Single Visualization Technique for Displaying Multiple Metabolite-Phenotype Associations. Metabolites 2019, 9, 128. [CrossRef] [PubMed] 